\title{
The Clan and the Corporation: Sustaining Cooperation in China and Europe
}

\author{
Avner Greif \\ Guido Tabellini
}

\author{
CESIFO WORKING PAPER NO. 5233 \\ CATEgory 6: Fiscal POLICY, MaCROECONOMICS AND GROWTH \\ FEBRUARY 2015
}
An electronic version of the paper may be downloaded
- from the SSRN website:
- from the RePEc website:
- from the CESifo website:
www.SSRN.com
Www.RePEc.org
www.CESifo-group.org/wp




\title{
The Clan and the Corporation: Sustaining Cooperation in China and Europe
}

\begin{abstract}
Over the last millennium, the clan and the corporation have been the loci of cooperation in China and Europe respectively. This paper examines - analytically and historically - the cultural and institutional co-evolution that led to this bifurcation. We highlight that groups with which individuals identify are basic units of cooperation. Such loyalty groups influence institutional development because intra-group moral commitment reduces enforcement cost implying a comparative advantage in pursuing collective actions. Loyalty groups perpetuate due to positive feedbacks between morality, institutions, and the implied pattern of cooperation.
\end{abstract}

JEL-Code: N000, A100.

\author{
Avner Greif \\ Department of Economics \\ Stanford University \\ USA - Stanford, 94305, CA \\ avner@stanford.edu
}

\author{
Guido Tabellini \\ Department of Economics / IGIER \\ Bocconi University \\ Via Sarfatti 25 \\ Italy-20136 Milan \\ guido.tabellini@unibocconi.it
}

First version: October 2011

This version: Feb 2015

We thank CIFAR and the ERC for financial support, Chen Cheng, Alessandra Fenizia, Claudio Sormani and Edoardo Teso for excellent research assistance, and Marco Croci, Carsten Herrmann-Pillath, Debin Ma, James Kai-sing Kung, Roy Mill, Joel Mokyr, Carol Shiue, Yannay Spitzer, Philip Thai, George Zhijian Qiao, and Yiqing Xing for comments. We particularly benefited from the generosity of Ying Bai and James Kai-sing Kung who directed us to the data regarding China, and we are extremely grateful to George Zhijian Qiao (Stanford University) and Prof. Hongzhong Yan (chair of the economic history department in Shanghai University of Finance and Economics) for valuable discussions and for the dataset on Chinese genealogies. 


\section{Contents}

1 Introduction $\quad 2$

2 Cooperation in Pre-modern China and Europe $\quad 5$

2.1 The activities of clans and corporations . . . . . . . . . . . . . 6

2.2 Enforcement of cooperation . . . . . . . . . . . . . . . 8

3 A Model of Cultural and Institutional Bifurcation $\quad 9$

3.1 Static Analysis . . . . . . . . . . . . . . . . . . . 10

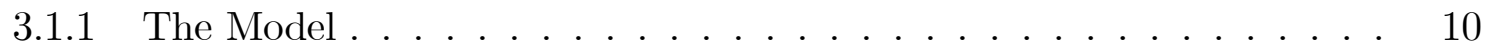

3.1.2 Equilibrium City Size . . . . . . . . . . . . . . 12

3.2 Dynamics . . . . . . . . . . . . . . . . . . . . . . . . . . . . . . . . . . . .

3.2.1 The Dynamic Model . . . . . . . . . . . . . . 16

3.2.2 Dynamic Equilibrium with Full Sorting . . . . . . . . . . . . . . . 17

3.2.3 Dynamic Equilibrium with Segregation in the Clan . . . . . . . . . . 17

3.2.4 Dynamic Equilibrium with Segregation in the City . . . . . . . . . 18

3.3 Discussion . . . . . . . . . . . . . . . . . . . . . 19

4 Historical analysis $\quad 20$

4.1 The origins of clans and corporations . . . . . . . . . . . . . . . 20

4.1.1 The emergence of clans and corporations . . . . . . . . . . . . 20

4.1.2 Migration and the choice of social organizations . . . . . . . . . . 24

4.2 Morality and kinship groups . . . . . . . . . . . . . . . . . . 27

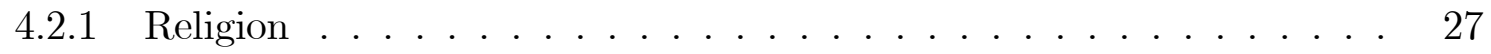

4.2 .2 Criminal law . . . . . . . . . . . . . . . . . . . 28

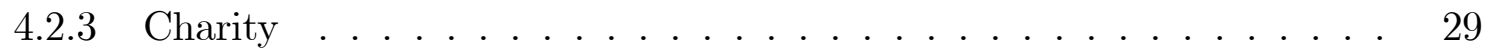

4.3 Complementary institutions . . . . . . . . . . . . . . . . . . . . . . . . . . . . . . . . .

4.3.1 Market institutions . . . . . . . . . . . . . . . . 31

4.3 .2 State institutions . . . . . . . . . . . . . . . . 34

5 Persistence of Kinship Ties in Modern China $\quad 37$

5.1 The re-emergence of clans in China . . . . . . . . . . . . . . . . . . 37

5.2 Cultural persistence . . . . . . . . . . . . . . . . . 40

6 Concluding Remarks $\quad 42$

$\begin{array}{lll}7 & \text { References } & 44\end{array}$

8 Online Appendix $\quad \mathbf{5 4}$

8.0.1 Proof of Lemma 1 . . . . . . . . . . . . . . . . . . 54

8.0.2 Proof of Proposition $2 \ldots \ldots \ldots \ldots$

8.0.3 Proof of Proposition $4 \ldots \ldots \ldots \ldots$

8.0.4 Proof of Proposition $5 \ldots \ldots \ldots$. . . . . . . . . . . . 59 


\section{Introduction}

Although we often take it for granted, the state as we know it is a relatively recent institution. How was society organized when the state was much weaker or nonexistent? Who fulfilled the need to provide the most basic public goods and enforce a minimum of cooperation? These general questions are important not just for historical reasons, but also to understand the functioning of the modern state, since state institutions often evolved gradually from more primitive and pre-existing organizations.

In this paper we contrast two social organizations that emerged in pre-modern China and Europe respectively: the clan and the corporation. The Chinese clan is an organization based on kinship. It consists of individuals or families with common descent who share reciprocal loyalty and obligations to each other. The European corporation is a voluntary association between unrelated individuals established to pursue common interests. The foremost historical example is the independent city, others are guilds, communes, and business associations. Both organizations perform similar functions: they enforce cooperation among members, provide local public or club goods, and coordinate interactions with the market and with the state. Yet, they are built on very different criteria and operate quite distinctly. Enforcement of cooperation inside a clan exploits reciprocal moral obligations and personal interactions, whereas corporations typically rely on more impersonal enforcement procedures.

How can we explain the emergence and consolidation of such different social organizations in these two parts of the world? And how did they influence subsequent institutional evolutions? These are the questions addressed in this paper. Our main general insight is that different initial conditions in cultural traits, at a critical historical juncture, facilitated the emergence of different organizational forms in these two societies. Their subsequent proliferation reinforced the different cultural traits, leading to a divergence of culture and institutions between China and Europe that persists in modern times.

The wide scope of our analysis forces us to examine long periods of time and to compare broad social systems. For this reason, we rely on a mix of theory, quantitative evidence, and historical narrative. With the help of the theory, we identify key features of social organizations and cultural practices, and derive specific predictions about their equilibrium interactions. We then compare various institutions in each society over the long run, in light of these predictions. The long span of history provides inter- and intra-society variations that facilitate identifying causal relations.

Our theoretical approach rests on three central ideas. First, social organizations are important because they constitute basic units of cooperation. Second, social organizations are also held together by mutual moral obligations and group-specific morality, not just by economic interests or other common attributes. Third, although very persistent, the forces that glue individuals to a group are not immutable. Individuals tend to vote with their feet and join or abandon a group, and the institutional and cultural foundations of social groups evolve endogenously over time. These central ideas can be used to explore a variety of settings, and not just the institutional development of China and Europe.

We formulate a simple model in which individuals with given but different cultural traits choose their social affiliation, to their clan or to a city (the foremost corporation). Both organizations supply public goods, but they rely on different enforcement methods. The equilibrium size of these organizations reflects the diffusion of cultural traits, since different 
traits (loyalty to kin vs. generalized morality) confer a comparative advantage to one or the other organization. We then study the dynamic evolution of culture and organizations. Overtime the distribution of cultural traits across individuals reflects their social affiliation: we assume that individuals affiliated with clans are more likely to give rise to newborns who are loyal to their clan, while individuals born in a city tend to share notions of generalized morality. These dynamic complementarities imply multiple steady states that can only be reached from different initial conditions. Two otherwise identical societies that differ only in the initial distributions of moral traits could evolve along different self-reinforcing trajectories of moralities, organizational forms, and enforcement institutions. Initial diffusion of kinbased morality leads to a steady state where clan loyalty is widespread, the clan provides public goods, the share of the population organized in a corporation is small, and intraorganization institutions are weak. Conversely, if generalized morality is initially widespread, the organization of society moves to an opposite steady state, where independent cities (or other corporations) are the main providers of public goods.

We then compare the evolution of social organizations in China and Europe in light of these predictions. The historical analysis reveals that clans and corporations began to proliferate by the end of the first millennium, when and where the state was weak or absent and the need for basic public good provision was unfulfilled by other institutions. This was particularly the case in areas of intense migration; the process by which new settlers chose their social affiliations and built social organizations resembles the bottom-up process captured by the model, and was not influenced by political interferences or other institutions.

To identify cultural traits, we rely on three sets of historical indicators: religion, legal codes, and charity organizations. Religious beliefs around the 9th century differed sharply in the two societies, and they implied different notions of morality: primarily directed towards kin in China, more impersonal and generalized in Europe. This created different loyalty groups with which individuals identified, and conferred a comparative advantage in enforcing cooperation to distinct social organizations. The moral code associated with the clan facilitated kin-based cooperation. The European corporation, in contrast, was built on impersonal rules consistent with generalized morality, and more appropriate to enforce cooperation between unrelated individuals. The analysis of legal codes and charities provides additional evidence of these differences, and confirms that the cultural divergence between China and Europe became more pronounced over time. In China, the predominant role of clans and of kin-based interactions reinforced moral obligations towards kin. In Europe, the proliferation of open and heterogeneous communities such as independent cities strengthened notions of generalized morality and the rule of law.

The evolution of other market and state institutions, and their interaction with clans and corporations, further reinforced this divergence. In both regions, the state relied on the predominant social organization to delegate administrative and economic tasks. The Chinese state retreated from the countryside and increasingly focused on providing global public goods. The system was effective in supporting an expanding population, industry and trade, as well as a large army and territorial expansion. The dichotomy between clans and state administration remained a weak point of Chinese institutional evolution, however. In Europe, by contrast, the integration of corporations into the state administration was facilitated by a tradition in which individuals unrelated by blood cooperated based on generalized morality and legal enforcement. We leave to a follow-up project exploring how these institu- 
tional evolutions affected subsequent economic and political outcomes. Yet, the preliminary evidence in this paper suggests that the distinct social organizations that prevailed in China and Europe had lasting effects on the pattern of their economic and political development.

Finally, and motivated by this conclusion, we provide quantitative evidence that cultural differences between China and Europe persist today, and that in China kinship based organizations have survived the shock of the communist revolution and its ideology of class-based morality. In 1949 the clans were officially disbanded, their property taken, their rules invalidated, and genealogy roles were burned for heating. Yet, clans reemerged in China after 1979 , and they probably contributed to the success of the pro-market reforms supplementing the weak legal institutions.

This paper builds on a recent but rapidly growing literature on the joint analysis of culture and institutions (see Greif 2006, Tabellini 2008a, 2008b; Nunn 2012 provides a recent survey). To that literature, we add a focus on endogenous social organizations and a comparative historical analysis of China and Europe.

There is a long-standing debate on the distinct developmental trajectories in the West and China. Recent contributions include Pomeranz (2000), Brenner and Isett (2002), Voigtländer and Voth (2013), Sng (2011), and Rosenthal and Wong (2011). See also the reviews by Deng (2000) and Brandt, Ma, and Rawski (2011-13). Much of this debate has focused on external environmental factors or the role of the state, however, neglecting the social organizations which are the focus of this paper. There is, however, a small and growing litereature on the comparative economic history of social organizations that focuses, in particular on the corporation (e.g., Greif, 1994, 2005, 2006a; Kuran 2005, Guinnane et al., 2007).

Karl Marx was perhaps the first to view social organizations as means of control. According to this interpretation, the distinctions among social organizations in China and Europe are inconsequential because they serve the same function. Those who control the means of production create social organizations to perpetuate their control. The Chinese and European elites relied on the clan and the corporations to maintain their power. The Chinese kinship groups, for example, fostered elite control by holding the kinship group liable for actions of their members. ${ }^{1}$ Similarly, the European elite strategically created corporations to align interests, influence wealth distribution, and maintain political order. ${ }^{2}$ These are important insights and we return to them below. Yet, the elite-control argument neither explains the timing of these organizations' emergence nor the forms they took. Moreover, the evidence contradicts the view that the clans and corporations were passive subservient to whim of elites. In fact, clans in China and cities in Europe often opposed the state and its officials. Furthermore, self-governed European cities and Chinese clans were important agents of economic and political changes that adversely influenced dominant elites.

Max Weber (1968) advanced the conjecture that cultural distinctions lead to different social organizations: Chinese culture emphasized kinship, while European culture emphasized individualism. Although this conjecture is appealing and our paper builds on it, it is also historically and conceptually unsatisfactory. Historically, the cultural distinctions prevailed long before the emergence of clans and corporations in China and Europe. Why did its

\footnotetext{
${ }^{1}$ For a recent articulation on this perspective, see Acemoglu and Robinson (2012). For a review and discussion of the case of China see Szonyi (2002, pp. 57-68).

${ }^{2}$ See, for example, North, Wallis and Weingast (2009) and Jha (2010).
} 
manifestations emerge when they did? Moreover, culture is endogenous and slowly adapts to the prevailing social organizations. Any cultural explanation is incomplete without an analysis of why it persists, despite cultural entrepreneurs and deviants who challenge the dominating culture and provide alternatives, as was the case in China and Europe.

Although the above two views are considered mutually exclusive, our analysis combines some of their core insights. Organizations can influence outcomes only to the extent that they influence behavior beyond what is achievable by each individual member acting separately. Their members should be motivated to take actions that otherwise they would not undertake. The Chinese elite could use kinship groups to foster control only because kinship mattered. The European corporation could aggregate more heterogeneous groups because there was a cultural predisposition of loyalty also towards unrelated individuals. Culture influences what is socially acceptable and institutionally feasible. At the same time, the form of social organizations preserves and reinforces specific cultural traits. Social organizations and culture are mutually constitutive. In other words, complementarities among cultural, social, and institutional features imply mutually reinforcing effects.

The outline of the paper is as follows. Section 2 describes the pattern of cooperation in pre-modern China and Europe, illustrating the central role of the clan and corporation respectively. Section 3 presents and solves our theoretical model, first in a static version with given cultural traits, and then in a dynamic version where culture adapts to the social organizations. Section 4 contains our historical analysis: first it describes the timing and circumstances that led to the emergence of clans and corporations; then it documents the initial conditions and subsequent evolution of cultural traits; and finally it describes the interactions with market and state institutions. Section 5 documents the re-emergence of clans and the cultural persistence in modern China. Sections 6 concludes.

\section{Cooperation in Pre-modern China and Europe}

This section contrasts the organization of cooperation in pre-modern China and Europe roughly since the 9th century. In China, kinship groups were the key social organization. Among the kinship-based Chinese group are the descent group (whose members' institutionalized interactions were limited to ancestral rites or the compilation of genealogy) and the lineage (a descent group that shared assets). The term clan is used here generically to refer to kinship groups composed of (some or all) the households of patrilineal kin who trace their origin to a (self-proclaimed) common male ancestor. Although clan members live in many households, they share a genealogy delineating their relations. ${ }^{3}$

In pre-modern Europe, in contrast, units of cooperation were based on common interest rather than common ancestry. We refer to these units with the generic term corporation. The European corporations were horizontal voluntary associations, such as independent cities, communes, guilds, universities, friendly societies, parishes, and, eventually also business corporations.

Both clans and corporations are permanent social organizations whose perpetuation does not depend on the participation of a particular member. Clans and corporations differ, however, in the principles guiding the selection of members. Membership in clans is based on

\footnotetext{
${ }^{3}$ See, for example, Watson, (1982) and Ebrey and Watson (1986).
} 
kinship, while membership in a corporation is based on common interest. Thus, clan members have shared interest because of their membership, while memberships in corporations is due to common interest regardless of kinship.

\subsection{The activities of clans and corporations}

In China, after their emergence, clans became increasingly important providers of public goods and social services. These included poor-relief and social safety nets, lending money to members in need, education, religious services, building bridges, protecting property rights, and administering justice. ${ }^{4}$ To illustrate intra-clan cooperation, consider the 18th century clan of Li of Wenchuan from the Fujian province. In 1753 the clan's elders considered establishing an ancestor hall in the prefectural city so that "scholars [members of the clan] taking the [public office] examinations [will] obtain the blessing of a quiet place to live ... [and] members of the lineage [going to the city for any reason] will ... have ... a peaceful place to stay" (Zhenman, 1992, p. 135). The concern with members of the clan taking the public office exams highlights clan-based cooperation in providing education. A clan gained access to political power when a member passed the exams and thus, in general, they "supported schools, held usually in ancestral halls." (Watson, 1982, p. 601). In the early 11 th century, the Song dynasty had between 170,000 to 210,000 students in state schools. Four hundred years later, in the early 16th century, there were only about 31,000 students supported by the state out of a much larger population (Liu, 2005). Clans stepped in and, as was the case in rural Guangdong, "until the 1920s the chances of a peasant attaining a minimal level of literacy ... depended very largely on access to lineage-sponsored schools" (Watson, 1982, p. 601).

By the 19th century, intra-clan cooperation was so common that Westerners considered it the hallmark of Chinese culture. A well circulated English book about China declared in 1869 that the "Chinese nation is divided into" clans and "these clans are bound to assist each other in any way that may be required". ${ }^{5}$ There is no comprehensive data on the share of the population with clan affiliation in various periods, but we know that in the Jiangxi province more than half the population belonged to clan organizations in the 18th century (Rowe, 1998, p. 386). Although clans were weaker in the north of China, multi-clan villages in this part of China had a fictive kinship structure that excluded newcomers as late as the 20th century. ${ }^{6}$

The importance of clans in supporting cooperation is also evident from the creation of fictional kinship groups. The clan of $\mathrm{Li}$ in Wenchuan provides an example of what Zhenman called a contractual clan. Everyone who shared the clan's surname could have bought a share (when offered) in return to proportional amount of prayers for the souls of his ancestors. When cooperation with kin was insufficient, the boundaries of the group was extended to individuals who were 'closer' to kin than others, and particularly to those with close place of residence or origin. The further away one had to move from kin-like relations, more assertive means were used to create kin-like relations. These means included adopting an

\footnotetext{
${ }^{4}$ For recent surveys and contributions, see Ruskola (2000), Cohen (1990), Szonyi (2002), and Faure (2007).

${ }^{5}$ Reynold's (1869), 42, p. 157.

${ }^{6}$ On North China, see Cohen (1990).
} 
adult, adopting the same surname, developing a myth of common origin, creating a clantrust, etc.. Personal, clan-like relations, whether real or imaginary, were considered essential for cooperation.

In Europe corporations fulfilled similar functions. Cities provided legal enforcement, schooling, commercial infrastructure, and other local public goods (e.g., Pirenne, 1969), while monasteries provided poor relief, universities educated, and guilds regulated production. In fact, establishing a corporation became the common way of achieving collective goals. For example, the Crusades required large scale cooperation over long distances. This was achieved via corporations in the form of military orders. The Order of the Knights Templar, for example, played a key role in defending the Crusaders' states (Barber, 1995). Another order, that of the Knights Hospitaler, ruled the islands of Rhodes and Malta while the Teutonic Order spearheaded the Crusaders in Eastern Europe, conquered and ruled Old Prussia.

Even when organizations in China and Europe had seemingly identical purposes, their origin and membership were strikingly different. In particular, in pre-modern Europe, city dwellers with the same occupation were organized in craft guilds, a corporation while in China, by contrast, craftsmen were organized by their place of origin. ${ }^{7}$

In China, the place-of-origin craft guilds (huiguan or "club-houses") emerged during the Ming dynasty through a process indicative of the increasing importance of social organizations in supporting cooperation. From at least the Song Dynasty (960-1279), there were occupation groups in Chinese cities. These were not self-governed, however: they had "headmen" (hangtou or hanglao) who were subservient to the authorities and functioned mainly as price setters and brokers. As clans emerged, they established hostels in main cities to accommodate their members taking the examinations for the civil service. We already discussed how the Li clan of Wenchuan established such club-house.

During the Ming dynasty, club-houses became self-governing guilds and membership in each guild was generally limited to those from a specific place of origin and not, as in Europe, to those with the same economic interest. The data set on Chinese guilds complied by Christine Moll-Murata (2008) contains 516 pre-1900 guilds; of these, 347 can be classified as common origin or common occupation, by their name. The large majority (73\%) of the pre-1800 guilds were based on common origin.

The common-origin guilds were founded to serve the collective interests of their members and, in particular, to counter the influence of the government-licensed brokers. To illustrate, the Canton guild (Xiancheng huiguan) in Beijing, founded in 1715, viewed price fixing as serving the collective interest (gong) of their members and not the selfish interest (si) of each. It explicitly noted its role in limiting the extractive capacity of the governmentally appointed brokers vis-a-vis the traders.

European style guilds, based exclusively on economic interests, became common in China only after 1850, but their number remained small relative to Europe. For all of China, the records reveal a mere 268 such guilds from 1655 to 1911 (Moll-Murata, 2008) while in n Venice and Naples alone, no less than 328 guilds were establishedl between 1220 and 1800 .

\footnotetext{
${ }^{7}$ The discussion of China is based on Liu (1988) and Moll-Murata (2008). For Europe, see, for example, the classical work by Ashley (1909). See Landa (1981) for discussion of such organizations in Chinese Diasporas.
} 
Relative to the population these cities had about one guild per 250 adult males around 1800 . In northern Netherlands, craft guilds numbered 1,374 by the year 1784, implying one guild per about 200 adult males working in the non-agricultural sector. ${ }^{8}$

\subsection{Enforcement of cooperation}

The different membership criteria of clans and corporations are reflected in how they enforced cooperation. Both clans and corporations often articulated an appropriate conduct, punishments for deviations, and the process of adjudication and sanctioning. Although seemingly similar, these enforcement methods were quite different.

In China, although clans had the legal rights to punish members for misconduct, clan rules were aimed at specifying the morally appropriate behavior, and therefore no punishment was specified for most transgressions. ${ }^{9}$ As one clan book rule states, "a clan without rules leaves its members with no moral standard of conduct to follow" (Liu, 1959, p. 22). Intraclan legal disputes were arbitrated by the elders, compromise was the goal, and harmony was the objective. The mutual moral obligations and the frequent interactions between kinrelated individuals, reduced the temptation to cheat or free ride on other clan members, thus reducing the potential gains from creating more formal enforcement institutions. ${ }^{10}$ The priority of custom over legal principles is evident from the Great Qing Code (of law) in which crime is defined as any action that "ought not to be done" (article 386 in the Great Qing Code).

In contrast, enforcement rules inside corporations generally relied on formal procedures, reflecting the weaker moral obligations within a group collected on the basis of common interest. Such formalities are most transparent in the European cities that developed legal codes to enforce cooperation. The late medieval urban communes transitioned from legal customs to legal codes, and from elected voluntary judges to professional ones (e.g. Clark, 1987). Self-governed cities adopted and enforced codes of law. In Germany alone, between 1143 and 1475, for example, 190 cities adopted one of the twenty different law codes that had been specified by the leading towns.

Differences in enforcement methods between clans and corporations (and cities in particular) are also evident from how they financed their operations. While the European cities relied on taxes and monopolies for revenue, Chinese clans relied on voluntary contributions to finance their activities. The Chinese 'clan trust' was first introduced during the Song Dynasty (960-1279) and it enabled clan members to jointly hold property. Trusts were endowed by wealthy clan members and some clans, particularly in the south, were very wealthy. In the north, lineage organizations had little, if any, property and their operation was financed by on-going contributions. In multi-clan villages the local temple collected contributions and assisted members of the local clans (Huang, 1985).

Summarizing, pre-modern Europe and China relied on very different social organizations to enforce cooperation in a variety of settings. The next section presents a model that

\footnotetext{
${ }^{8}$ Italy: Mocarelli (2008), table 1. Dutch republic De Moor (2008), p. 189. Urban population Lowndes and Debrett (1789). Dutch calculations assumes that $50 \%$ of the population was employed in agriculture.

${ }^{9}$ Liu's (1959) classical study of the rules of 151 clans reveals that punishment was specified with respect to only $20 \%$ of the rules. See also Ma (2007).

${ }^{10}$ See review in Ma (2007). Cf. Zelin et al (2004).
} 
explains how these patterns could have evolved out of different initial conditions, and explores the mutual reinforcement of culture and social organizations.

\section{A Model of Cultural and Institutional Bifurcation}

How can we explain the emergence and diffusion of such different social organizations? And what do these social structures imply for the pattern of social and economic interactions? This section studies a simple theoretical model that attempts to answer these questions.

Our starting point is the idea that the different membership rules for clans and corporations have key implications for how cooperation is enforced within the group. A kinship based organization can rely on enforcement methods that take advantage of its members' strong reciprocal moral obligations. Members of a common interest organization, instead, have weaker and impersonal moral obligations; as such, the organization has to rely on more formal and expensive enforcement procedures.

We embed this idea in a model in which membership to a clan or a corporation is freely chosen by individuals, based on convenience and the intensity of their moral obligations. Individuals with given but heterogeneous morality choose to interact with their kin (forming a clan), or with non-kin (giving rise to a corporation). The role of the clan and the corporation is to sustain cooperation in the provision of a local public good to their members (club goods). A larger organization is more attractive, because of economies of scale in public good provision, inducing a strategic complementarity. The main result of this bottom-up process is that the equilibrium size of each organization depends on the initial distribution of values in society. The clan emerges as a dominant social organization if a large fraction of the population has strong moral ties to their kin, while the corporation is favored if moral ties are impersonal albeit, weaker.

We then allow the distribution of individual moral traits to be shaped by the pattern of social interactions. Clan based interactions foster loyalty to the kin, while interactions within a common interest organization spread generalized morality. This gives rise to a joint dynamics of organizations and values, that can explain the institutional and cultural bifurcation between China and Europe.

The model refers to the alternative organizational structures as the city and the clan, because the former epitomizes the European corporations, while the latter is the main Chinese kinship-based social organization. The city is also the historically most important and comprehensive common interest organization. As explained in the next section, this interpretation is consistent with the main historical phenomenon we want to capture: these different organizations emerged during a period of intense migration, where settlers were choosing whether to settle in a city or to mainly interact with a clan. This is only one of the possible interpretations, however. The term city does not necessarily refer to a group of individuals living in an urban settlement, but to any social organization in which individuals unrelated by kinship interact on a regular basis and have the capacity to organize themselves institutionally. Similarly, a clan does not necessarily refer to its Chinese rural historical form, but to any organization whose members are related by some innate attributes, such as kinship, childhood friendships, or common origin. In short, we use the terms city and clan to capture distinctions in social organizations, and not distinction between rural and urban settlement. 


\subsection{Static Analysis}

\subsubsection{The Model}

A population of fixed size $M$ is split in $M>1$ identical dynasties (or families). Each dynasty contains a continuum of individuals and the size of each dynasty is normalized to unity. Individuals live one period. At the beginning of their life, they choose whether to settle in the city or in their clan. There is a single city that can draw settlers from all dynasties, while the clan can only draw individuals belonging to a single dynasty; thus, there are several clans and one city. Settling in the city (rather than in the clan) gives to each individual an idiosyncratic extra benefit $\delta$, where $\delta$ is a random variable distributed within each dynasty according to a uniform distribution over the range $[0,1 / d]$, with $d>0$.

Each individual has a fixed endowment equal to 1. After having chosen his location (the city or the clan), he decides whether or not to contribute a fixed amount $\tau$ to the community where he settled, with $0<\tau<1$. Individuals draw utility from two sources (besides the random variable $\delta$ defined above). First, they enjoy a material benefit:

$$
v=1-t+H(g)
$$

where $1-t$ refers to private consumption, with $t=\tau, 0$ depending on the individual choice, and $g$ denotes a public good supplied by the community of residence (the city or the clan). The function $H($.$) is continuously differentiable, concave, and strictly increasing,$ with $H(0)=0$ and $H_{g}(\tau M)>1 / M$ (this last condition implies that the public good is sufficiently productive from a social point of view).

Second, each individual also enjoys a psychological benefit $p$ whenever it contributes a positive amount to the community with which it identifies. ${ }^{11}$ Irrespective of where they choose to settle, individuals can identify with either their clan or with the city. In each dynasty there is a given fraction of individuals who identify only with the clan, and the remaining fraction identifies with the community where they choose to settle, irrespective of whether it is their clan or the city. For shortness, we call them the "clannish type" and the "generalist type" respectively. The psychological benefit of giving to the community with which individuals identify differs by type; specifically, we assume that $p=\lambda$ for a clannish type and $p=\gamma$ for a generalist, with $\lambda>\tau>\gamma>0$. Thus, identification with the clan is stronger for the clannish type than for the generalist, in the sense that the former draws a more intense psychological reward from participating in the provision of the clan public good. The generalist on the other hand draws the same psychological benefit from contributing to the city or to the clan, but it is a weaker benefit. By assumption, the intrinsic motivation of the clannish type is so strong that they are willing to contribute to their clan (but not to the city) even without any external enforcement $(\lambda>\tau)$, while a generalist would choose not to contribute (neither to the clan nor the city) in the absence of enforcement $(\tau>\gamma)$. Note that individuals can only contribute to the community which they joined (and which we metaphorically associated with a place of residence). ${ }^{12}$ Moreover, individuals choose where

\footnotetext{
${ }^{11}$ An equivalent formulation would have each individual bearing a cost $p$ whenever it free rides or cheats on the community with which it identifies.

${ }^{12}$ Excluded by assumption is the possibility that one contributes to a faraway community or that a different members of a nuclear family live in different communities. This assumption is made for the ease of exposition.
} 
to settle, while nature chooses their type. Of course, as described below, identification (or morality) is one determinant of whether individuals choose to settle in the clan or in the city. For simplicity, the distribution of the idiosyncratic parameter $\delta$ is the same for clannish and generalist type.

A simple enforcement technology is available: by spending an amount $e \geq \tau$ of public resources, individuals who do not contribute are detected with probability $q$. If caught, their endowment is destroyed, so that their material utility is just equal to $H(g)$ (thus even if caught an individual continues to enjoy the benefits of the public good, or equivalently the public good is non-excludable). The assumption $e \geq \tau$ implies that it would never be optimal to exploit this enforcement technology in the clan, because the clan is too small. If external enforcement is used, it would only be in the city. In this regard, we also assume that:

$$
\tau>q \geq \tau-\gamma
$$

This implies that, if enforcement is used in the city, it is powerful enough to induce contributions by the generalists, but not by the clannish type. We assume that, whenever it is optimal to do so, the city exploits this enforcement technology. Table 1 introduces the notation that will be used below, where each cell refers to a combination of preferences and location, where the $\lambda$ and $\gamma$ superscripts denote preferences, while the $n$ (for clan) and $y$ (for city) superscripts refer to location.

Table 1

\section{Location}

$\begin{array}{llll}\text { Type } & \text { clan } & \text { city } & \text { total } \\ \text { clannish } & x^{\lambda n} & x^{\lambda y} & x^{\lambda} \\ \text { generalist } & x^{\gamma n} & x^{\gamma y} & x^{\gamma} \\ \text { total } & x^{n} & x^{y} & 1\end{array}$

Thus, $x^{\lambda n}$ is the fraction of individuals who are of type $\lambda$ (clannish) and settle in the clan, $x^{\lambda y}$ the fraction who is of type $\lambda$ and lives in the city, and so on. The variables $x^{p}=x^{p n}+x^{p y}$, for $p=\lambda, \gamma$, denote the proportion of type $p$ in each dynasty and are chosen by nature. Similarly, $x^{y}=x^{\lambda y}+x^{\gamma y}=1-x^{n}$ denotes the fraction of each dynasty settling in the city, and it is determined in equilibrium, along with the proportions in each cell of Table 1.

With this notation and given the above assumptions, we can pin down the public good provision in the two communities. Given that only the clannish type contributes to the clan, the amount of public good provided in the clan is:

$$
g^{n}=\tau x^{\lambda n}
$$

Similarly, given that only the generalists contribute to the city, the amount of public good provided in the city is:

$$
\begin{aligned}
& g^{y}=\tau M x^{\gamma y}-e \text { if } x^{\gamma y}>e / M \tau \\
& g^{y}=0 \text { otherwise }
\end{aligned}
$$


where we have used the constraint that the enforcement technology can be used only if the city is large enough and it attracts a large enough fraction of generalist type.

Throughout we assume:

$$
1 / 2>e / M \tau \equiv \hat{e}
$$

This condition enables the existence of equilibria with small city size (i.e. less than half the population lives in the city). For reasons discussed below, we also assume:

$$
\tau M H_{g}(0)<1 / d<\lambda+\gamma+q-2 \tau
$$

The timing of events is as follows: Each individual observes his type and then chooses whether to settle in his clan or in the city. Individuals then observe the community size (and hence whether the enforcement technology is feasible or not) and choose whether or not to contribute to the community budget. Payoffs are realized. An equilibrium is defined as a distribution of individuals across communities and an allocation of resources such that: i) All individuals have optimally chosen whether to settle in their clan or in the city, given their type and correctly anticipating all subsequent events. ii) All individuals have optimally chosen whether or not to contribute to the community budget, given their type, their community size, and the distribution of types in the clans and in the city. We only consider symmetric equilibria where all clans have the same size and the same distribution of types.

\subsubsection{Equilibrium City Size}

We now discuss how different types are distributed amongst the city or the clans. In general, many equilibria are possible, depending on parameter values, and multiple equilibria can also occur. In particular, we cannot rule out equilibria in which the whole population settles in the same community (city or clans). The reason is that there are economies of scale in public good provision. Thus, if I expect everyone else to settle in the city (or in the clan), then it is also optimal for me to do so.

In this subsection we characterize the possible equilibria, paying particular attention to equilibria where city and clans coexist. We need some additional notation. Let $z=n, y$ denote the community of choice, namely the clan $(n)$ or the city $(y)$. As before, let $p=\lambda, \gamma$ denote the preference type, namely clannish $(\lambda)$ or generalist $(\gamma)$. Expected equilibrium welfare of type $p$ in community $z$ is a known function of the composition of the population settling in community $z$, namely: $W^{p z}\left(x^{\lambda z}, x^{\gamma z}\right)$, where $x^{\lambda z}$ denotes the fraction of $\lambda$ type in each dynasty who have chosen community $z$, and $x^{\gamma z}$ denotes the fraction of $\gamma$ type in each dynasty who have chosen that same community - see figure 2 .

Let $\delta^{p}$ denote the value of $\delta$ that leaves type $p$ indifferent between the clan and the city, for $p=\lambda, \gamma$. That is, $\delta^{p}$ is obtained by setting $W^{p n}=W^{p y}$ and hence it is a known function of $x^{p n}, x^{p y}, p=\lambda, \gamma$. The appendix proves:

Lemma $1 \delta^{\lambda}=\delta^{\gamma}+a$, where $a \equiv \lambda+\gamma+q-2 \tau>0$

The last inequality follows from previous assumptions about parameter values. It implies that the attractiveness of the clan compared to the city is always higher for the clannish type than for the generalists, given that they have the same realization of $\delta$, for all possible distri-

bution of players across communities. This result is important, because it has implications 
about the relative distribution of types across communities in equilibrium. The condition $\lambda>\tau$ that gives rise to $a>0$ means that the amount to be contributed is small relative to the intrinsic reward from not cheating in the clan. This implies that the temptation to free ride is not so strong that the clannish types are easily attracted to the city where they can free ride on the generalists.

This notation enables us to express the fraction of individuals of each type $p=\lambda, \gamma$ that prefer to be in the city or clan respectively as:

$$
\begin{aligned}
& x^{p n}=\operatorname{Pr}\left(\delta \leq \delta^{p}\right) x^{p} \\
& x^{p y}=\operatorname{Pr}\left(\delta>\delta^{p}\right) x^{p}=1-x^{p n}
\end{aligned}
$$

Given the assumed distribution of $\delta$, we thus have:

$$
\begin{array}{ll}
x^{p n}=d \delta^{p} x^{p} & \text { if } \delta^{p} \in[0,1 / d], \\
x^{p n}=0 & \text { if } \delta^{p} \leq 0, \\
x^{p n}=x^{p} & \text { if } \delta^{p} \geq 1 / d
\end{array}
$$

and correspondingly for $x^{p y}$.

There are five possible kinds of equilibria, and some of them can exist under the same configuration of parameter values (i.e. we cannot rule out multiple equilibria). In each equilibrium, city size (and hence clan size) is given by a different expression.

(i) First, as already stated, we could have an equilibrium in which everyone joins their clan. By Lemma 1 this requires $\delta^{\gamma} \geq 1 / d$. Here city size is 0 .

(ii) Second, we could have the opposite situation, where everyone is in the city. By Lemma 1 , this requires $\delta^{\lambda} \leq 0$. Here city size is the full population.

(iii) Third, we could have an equilibrium with full sorting, where all the clannish agents are in the clan, while all the generalists are in the city. This requires $\delta^{\lambda} \geq 1 / d$ and $\delta^{\gamma} \leq 0$. This too could be an equilibrium, for instance if $\lambda$ is large enough and $1 / d$ is small enough. Here city size is $M x^{\gamma}$, namely it coincides with the generalists' population.

(iv) Fourth, we could have an equilibrium with segregation, where all the clannish types are segregated in the clan while the generalists join both communities. This requires $\delta^{\lambda} \geq 1 / d$ and $1 / d>\delta^{\gamma} \geq 0$. Here, city size is $M x^{\gamma y}$ (the fraction of generalists settling in the city), which in turn is pinned down by the generalist types' indifference condition.

(v) Fifth, we could have the opposite equilibrium with segregation, namely the generalists are segregated in the city, while the clannish types join both locations. This requires $0<$ $\delta^{\lambda}<1 / d$ and $\delta^{\gamma} \leq 0$. Here, city size is proportional to $x^{\gamma}+x^{\lambda y}$, and $x^{\lambda y}$ is pinned down by the clannish type' indifference condition.

Note that Lemma 1 rules out an equilibrium with full sorting where all the clannish types prefer to be in the city, while the generalists all prefer to be in the clan (i.e. the opposite of equilibrium (iii)). Moreover, Lemma 1 plus the second inequality in (C1) rule out the equilibrium in which both types are present in both the clan and the city. ${ }^{13}$

It is tempting to interpret these admissible equilibria as reflecting a historical transition

\footnotetext{
${ }^{13}$ In an equilibrium in which both types are present in both locations we should have $1 / d>\delta^{p}>0$, for $p=\lambda, \gamma$. But by Lemma 1 this is impossible if the second inequality in condition (C1) holds.
} 
that accompanies the growth in the size of cities. One can think of an early situation where everyone lived in a clan-based society (equilibrium (i)). Then, for a variety of exogenous reasons (trade opportunities or defense) the city becomes more appealing (the distribution of the random variable $\delta$ shifts to the right), and some - but not all - generalist types are attracted to the city, so that we move to equilibrium (iv). As the city becomes even more attractive (as the distribution of $\delta$ keeps moving right), all the generalist types move to the city, and we shift to the equilibrium with full sorting (equilibrium (iii)). If the attractiveness of the city rises further, eventually the city becomes appealing even for the clannish types, and we shift to equilibrium (v), until the last step where all the clannish types have moved to the city and we are in equilibrium (ii). This interpretation has many loose ends, however. First, because everything occurs in reaction to a change in an exogenous parameter (the distribution of $\delta$ ) on which the theory has nothing to say. Second, the theory is silent about equilibrium selection (i.e., we cannot explain how we move from one equilibrium to another).

Rather than pursuing this interpretation, therefore, in the next section we introduce an explicit source of equilibrium dynamics through changing preferences (values). We then study how changing preferences interact with the distribution of individuals across communities, within the same equilibrium.

In preparation for that, here we ask how the existence of the equilibrium and equilibrium city size depend on the preference composition of the population (the parameter $x^{\lambda}$ in the model). In the first two kinds of equilibria, the answer is immediate. In these two equilibria the whole population is concentrated in a single location (the clan or the city), and thus city size cannot depend on the composition of the population. Moreover, as discussed above, these equilibria always exist for large configurations of parameter values and for any preference composition of the population, as captured by $x^{\lambda}$.

The remaining three equilibria (with full sorting and segregation) only exist for some values of the fraction of the clannish types within each dynasty, $x^{\lambda}$. Each equilibrium exists if and only if $x^{\lambda}$ belongs to a specific sub-interval of $[0,1]$. Under conditions stated in the appendix, there are three contiguous and non-overlapping sub-intervals of $[0,1]$ such that, as $x^{\lambda}$ moves from the lowest to the highest sub-interval, the equilibrium shifts from segregation in the city, to full sorting, to segregation in the clan. More precisely, the appendix proves:

Proposition 2 Under conditions (A1-A4) in the appendix:

(i) The equilibrium with segregation in the city exists if and only if $x^{\lambda} \in\left(x^{\min }, \underline{x}\right)$, where $1 / 2>\underline{x}>x^{\min } \geq 0$

(ii) The equilibrium with full sorting exists if and only if $x^{\lambda} \in[\underline{x}, \bar{x}]$, where $1>\bar{x}>$ $1 / 2>\underline{x}>0$

(iii) The equilibrium with segregation in the clan exists if and only if $x^{\lambda} \in\left(\bar{x}, x^{\max }\right)$, where $1-\hat{e}>x^{\max }>\bar{x}$.

This Proposition is depicted in figure 1 and the thresholds of each interval are implicitly defined in the appendix.

$$
<<\text { Insert figure } 1 \text { around here }>>
$$

The appendix also proves that: 
Figure 1: Static Equilibrium Configration

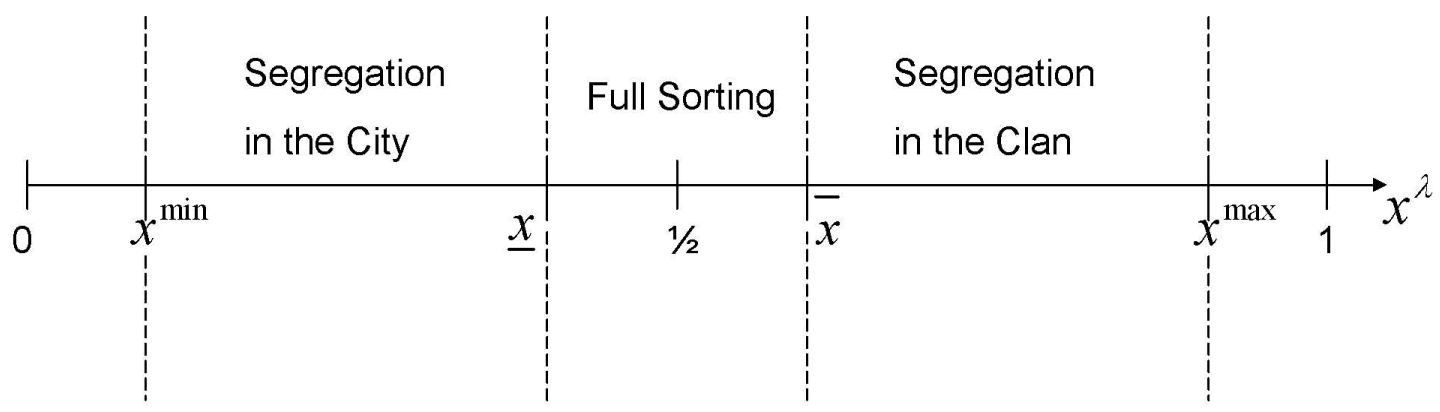

Proposition 3 Suppose that the first inequality in condition (C1) holds. Then, in all three equilibria described in Proposition 1, city size is a strictly decreasing function of $x^{\lambda}$, the fraction of clannish types within each dynasty.

The intuition is simple. Consider first the equilibrium with full sorting. Here the result is immediate: since all the clannish types settle in the clan while all the generalists settle in the city, an increase in $x^{\lambda}$ shrinks the fraction of generalists and hence city size shrinks too. Next, consider the equilibria with segregation. As the fraction of clannish types increases, the clan becomes more attractive compared to the city, because the amount of public goods increases in the clan or it shrinks in the city (recall that in equilibrium clannish types contribute to the public good in the clan but not in the city, while the generalists do the opposite). Hence, as $x^{\lambda}$ increases, some individuals who were close to indifference move from the city to the clan - which makes the clan even more attractive because it can better exploit the economies of scale in public goods provision compared to the city. The first inequality in condition (C1) is needed to make sure that, as this happens, equilibrium is restored because the distribution of the idiosyncratic preference parameter $\delta$ is sufficiently spread out.

Note that, as we shift from equilibrium (i) in Proposition 2, to equilibrium (ii), to equilibrium (iii), city size increases. Propositions 2 and 3 thus imply that, as the fraction of clannish types in the population increases, equilibrium city size shrinks (and clan size correspondingly increases), either as we shift from one equilibrium to the other, or within the same equilibrium.

\subsection{Dynamics}

The previous subsection pointed out how the distribution of values in the population affects the relative size of the clan vs. the city. In this section we discuss the opposite link: how the distribution of individuals between the clan and the city has implications for the endogenous evolution of values in society. We then discuss the two-way interaction between endogenous values and the relative size of the city vs. clan. 


\subsubsection{The Dynamic Model}

The parameter $x^{\lambda}$, measuring the fraction of clannish types within each dynasty, captures the distribution of values in society. Here we assume that this parameter is not fixed, but varies period after period reflecting the initial distribution of individuals between the clan and the city.

Suppose that the same environment described in the static model reproduces itself in each period with a constant population of one-period lived individuals. We can interpret individuals like households, and assume that each individual (or household) gives birth to a new individual (or household). The preferences ( $\lambda$ vs. $\gamma$ ) of the newborn individual reflect both the preferences of his parent, as well as the community (clan vs. city) where his parent lived. Specifically, we assume that a clannish parent living in the clan gives birth to a clannish son with probability $\bar{p} \geq 1 / 2$, and to a generalist son with probability $1-\bar{p}$. But a clannish parent living in the city gives rise to a clannish son with probability $\underline{p}<\bar{p}$, and to a generalist son with probability 1- $\underline{p}$. By symmetry, a generalist parent gives birth to a generalist son with probability $\bar{p}$ if he lives in the city, and with probability $\underline{p}$ if he lives in the clan, giving birth to a clannish son with complementary probabilities. These assumptions are meant to capture the idea that values are transmitted both within the family, as well as by the environment where one grows up. Parents are likely to transmit their values to their children, either deliberately or by setting an example - hence the assumption that $\bar{p} \geq 1 / 2$. But at the same time, growing up in the clan is likely to foster loyalty to and identification with the clan, while growing up in the city is likely to foster a more generalized respect for the rule of law, which in our setting is captured by the formulation of generalist preferences - hence the assumption that $\bar{p}>\underline{p}$. We also assume that $(\bar{p}+\underline{p}) / 2>1 / 2$, namely on average a clannish parent is still more likely to give rise to a clannish son than to a generalist, irrespective of where he lives. This assumption can be interpreted as saying that the influence of the family is stronger than that of the environment where one grew up. Finally, we assume that the distribution of the idiosyncratic $\delta$ parameter remains the same within each group of clannish and generalist types, irrespective of the relative size of the two groups.

Under these assumptions, the law of motion of the fraction of clannish types within each dynasty is (period $t+1$ refers to the newborn generation, while period $t$ refers to the parents' generation):

$$
x_{t+1}^{\lambda}=\bar{p} x_{t}^{\lambda n}+\underline{p} x_{t}^{\lambda y}+(1-\bar{p}) x^{\gamma y}+(1-\underline{p}) x_{t}^{\gamma n}
$$

The terms on the right hand side of (7) refer to the fraction of clannish sons born respectively from: clannish parents living in the clan; clannish parents living in the city; generalist parents

living in the city; generalist parents living in the clan. Recalling that $x_{t}^{\lambda}=x_{t}^{\lambda n}+x_{t}^{\lambda y}$ and that $x_{t}^{n}=x_{t}^{\lambda n}+x_{t}^{\gamma n}$, we can rewrite (7) as:

$$
x_{t+1}^{\lambda}=(1-\bar{p})+(\bar{p}+\underline{p}-1) x_{t}^{\lambda}+(\bar{p}-\underline{p}) x_{t}^{n}
$$

We can interpret equation (8) as follows: the first term on the right hand side, $(1-\bar{p})$, is the birth rate of clannish types that would occur if the previous generation only consisted of generalists living in the city. The second term is the differential birth rate between clannish and generalist parents, $(\bar{p}+\underline{p}-1)$, times the fraction of clannish parents. And the third 
term, $(\bar{p}-p)$, is the differential birth rate between parents living in the clan and the city, times the fraction of parents living in the clan.

Equation (8) can be combined with the results in the previous subsection to obtain a full dynamic analysis. In equilibrium, the composition of types within each dynasty is jointly determined with the allocation of individuals between the clan and the city. Since different equilibria are possible in the static part of the model, we have to consider each of them in turn. We neglect the trivial equilibria in which all the population is in a single location (city or clan), focusing instead on three static equilibria: the one with full sorting of types across communities, and the two equilibria with segregation of one type in one community.

\subsubsection{Dynamic Equilibrium with Full Sorting}

Consider first the equilibrium with full sorting of types across communities. This is simple, because the fraction of each dynasty settling in the city is just $x_{t}^{y}=1-x_{t}^{\lambda}-$ cf. (14) in the appendix. Hence, (8) reduces to:

$$
x_{t+1}^{\lambda}=(1-\bar{p})+(2 \bar{p}-1) x_{t}^{\lambda}
$$

Hence, this dynamic equation has a single steady state (denoted with an $s$ subscript), $x_{s}^{\lambda}=$ $1 / 2$. Not surprisingly, given the symmetry of the model, in the steady state the population is split in half, with all the generalists settling in the city and all the clannish types settling in the clan. Moreover, since $1>\bar{p} \geq 1 / 2$, the steady state is stable and the adjustment to the steady state is monotonic. While we remain in this equilibrium, any small permanent change in any of the parameters of the model has no effect (either temporary nor permanent) on the preference composition of the population, nor on the distribution of types across localities. Intuitively, with full sorting, the distribution of individuals across communities is entirely driven by their preferences, and cannot be affected by other parameters of the model. Hence the evolution of preferences in society is also entirely determined by its own past history and cannot reflect the influence of any other economic or social force.

By the results of the previous subsection, we have an equilibrium with full sorting if and only if $x_{t}^{\lambda} \in[\underline{x}, \bar{x}]$. Combining these dynamic results with those of the previous subsection we thus have:

Proposition 4 Suppose that the initial fraction of the clannish population, $x_{0}^{\lambda}$, is such that $x_{0}^{\lambda} \in[\underline{x}, \bar{x}]$. Then, over time the fraction of population with clannish values converges to $x_{s}^{\lambda}=1 / 2$, and both in the steady state and throughout the adjustment process all the clannish types settle in the clan while all the generalists settle in the city.

\subsubsection{Dynamic Equilibrium with Segregation in the Clan}

Next, consider the equilibrium where the clannish types are segregated in the clan, while the generalists are present in both the clan and the city. Here the derivation is more cumbersome, so we relegate it to the appendix. But the logic is simple. In this equilibrium, some generalists are attracted to the clan. This in turn influences the preferences of their offspring, which are more likely to become clannish types. Hence in the steady state the clannish population exceeds $1 / 2$. If the differential birth rate of clannish types between parents living in the clan 
and in the city (the term $(\bar{p}-p)$ ) is small, however, the steady state is stable. Hence, given that the initial condition of preferences is in the region corresponding to this equilibrium, society remains forever in this region and it converges to a steady state where the clannish types are a majority and city size is correspondingly small.

More precisely, let $x^{\lambda c}$ denote the steady state fraction of clannish types corresponding to this equilibrium. The appendix proves:

Proposition 5 Suppose that the initial fraction of the clannish population, $x_{0}^{\lambda}$, is such that $x_{0}^{\lambda} \in\left(\bar{x}, x^{\max }\right)$. Suppose further that $x^{\lambda c} \in\left(\bar{x}, x^{\max }\right)$ and that $(\bar{p}-p)$ is sufficiently small. Then, over time the fraction of population with clannish values converges monotonically to $x^{\lambda c}>1 / 2$, and both in the steady state and throughout the adjustment process all the clannish types settle in the clan while the generalists mix between the clan and the city.

As further discussed below, this steady state, with most of the population settling in the clan and only a minority in the city, captures the social organizations that prevailed in China - hence the $c$ superscript to denote this equilibrium.

Note that in this equilibrium, changes in the deep parameters of the model have permanent effects on the distribution of values in society - they impact on the steady state $x^{\lambda c}$. For instance, if the clan becomes more efficient in providing public goods to its members, more generalists are attracted to the clan, and over time a larger fraction of the population acquires clannish values.

\subsubsection{Dynamic Equilibrium with Segregation in the City}

Finally, consider the other equilibrium with segregation, where the generalist types are all in the city, while the clannish types are present in both communities. Here the logic is the reverse of that in the previous equilibrium. Since some clannish types are attracted to the city, their offspring are more likely to become generalists. Hence in the steady state the fraction of clannish types in the population ends up being a minority, and if $(\bar{p}-\underline{p})$ is small the steady state is stable. More precisely, let $x^{\lambda e}$ denote the steady state fraction of clannish types corresponding to this equilibrium. The appendix proves:

Proposition 6 Suppose that the initial fraction of the clannish population, $x_{0}^{\lambda}$, is such that $x_{0}^{\lambda} \in\left(x^{\min }, \underline{x}\right)$. Suppose further that $x^{\lambda e} \in\left(x^{\min }, \underline{x}\right)$ and that $(\bar{p}-p)$ is sufficiently small. Then, over time the fraction of population with clannish values converges monotonically to $x^{\lambda e}<1 / 2$, and both in the steady state and throughout the adjustment process all the generalist types settle in the city while the clannish mix between the clan and the city.

The specific conclusion that the majority of the population in this steady state settle in the city is due to the symmetrical structure of our model. Generally, in this steady state, more of the population settle in the city and less in the clan. It thus captures the social organizations that prevailed in Europe - hence the $e$ superscript to denote this equilibrium.

Here too, as in the previous equilibrium, the steady state distribution of values is affected by changes in the model's parameter: whatever makes the city more or less attractive to the clannish types has permanent effects on the proportion of individuals with clannish values. 


\subsection{Discussion}

Contrasting the last three propositions, we see that even small differences in initial cultural traits in otherwise identical societies can lead to lasting divergences in social organization, morality, and institutions. Moreover, temporary changes in the economic, cultural, or social underpinnings of the clan and the city can have a permanent impact on the trajectory of cultural, social, and institutional evolution.

Intertemporal complementarities imply that a society that starts out with a diffuse sense of loyalty to the clan is more likely to end up mainly relying on the clan to provide public goods, and only a small fraction of the population will be drawn towards the city. This situation corresponds to the equilibrium with segregation in the clan, where all the clannish types remain in the clan, and the generalists are distributed both in the clan and in the city.

In this equilibrium city size is small and clan size is large for two reasons. First, because the majority of the population has clannish values, these individuals find it optimal to remain in the clan. Second, because only some of the individuals with generalized morality (the generalists) are induced to stay in the city (these are the individuals with a high personal gain from being in the city, that is, a high realization of the $\delta$ parameter). Being large, the clan is more attractive than the city, benefiting from economies of scale in public good provision and the low cost of providing these goods based on limited morality. This situation perpetuates because the generalists living in the clan are more likely to have clannish offspring, compared to the generalists who associated with the city. We associate this equilibrium with the arrangements that prevailed in China, where loyalty to the clans that provided public goods was widespread.

A society that starts out with an emphasis on generalized morality is more likely to end up in the opposite situation, captured by the equilibrium with segregation in the city. Here all the generalists remain in the city, while the clannish types are found in both locations. The city is large (and the clan is small) for two reasons. First, the city's large population, drawn from many dynasties, can provide more public goods. Second, since there are many generalists, free riding does not undermine the provision of public goods. The city is thus more attractive than the clan even for some clannish types. Again, this situation preserves or strengthens itself over time, as the clannish types who are attracted to the city are more likely to give birth to generalist types. We associate this equilibrium to the situation in Europe.

These theoretical results draw attention to the key complementarity between culture and social organizations in the provision of public goods. To understand why social institutions evolved along different paths in China versus Europe, we need to focus on cultural differences in their respective early histories. Even if China and Europe had access to the same technologies, and neglecting the role of geography, international conflicts, and other environmental features, endogenous social institutions and cultural traits mutually reinforced each other. Different initial conditions in the diffusion of specific cultural traits can account for why social institutions and morality evolved in different directions in these two parts of the world.

We now turn to a more detailed historical analysis, in light of these implications. 


\section{Historical analysis}

\subsection{The origins of clans and corporations}

We start by discussing the origins of the social and institutional divergence between China and Europe. Identifying the period and circumstances of the initial divergence is important to assess the role of the key initial conditions, and to shed light on the correspondence between the model's assumptions and the historical details. We document that in both China and Europe the new social organizations gained prominence towards the end of the first millennium. This was a period of large scale migration and population expansion, when settlers could choose their social affiliations in an institutional vacuum and with little political interference, like in the bottom-up process described in the model.

\subsubsection{The emergence of clans and corporations}

When does the institutional divergence between China and Europe begin? Until the IXth century a distinct pattern of clans or corporations was not clearly discernible in China and Europe. It is only from the Xth century onwards that clans and corporations increasingly became the dominant social organizations in China and Europe respectively. Although clans in China and corporations in Europe existed prior to the second millennium, they gained prominence only subsequently.

Large kinship groups had been historically common and behaviorally-relevant in both China and Europe. In China, surnames groups were important at least since Confucius (551-479 BCE) viewed marriage as a "union of two surnames, in friendship and in love" (Dawson, 1915, p. 143). Prior to the Song dynasty (960-1279), however, the communal family appeared to have been the dominant unit of social organization. The communal family was a multigenerational household composed of all the nuclear patrilineal families tracing their origin to a particular male ancestor. The constituting household lived in the same dwelling, shared their property, and regulated their internal affairs. Prior to the IXth century, such large households were composed of relatively uniform family units, mainly farmers who cultivated lots of similar size.

Prior to the Song dynasty some aristocratic and courtesan families were organized as clans, which enabled them to practice primogeniture and to preserve concentration of wealth and power. ${ }^{14}$ Commoners, however, were generally not organized in clans. Moreover, the powerful noble clans were decimated in civil wars prior to the Song and the courtesan clans declined as well once the Tang dynasty (618-906) reformed the examination system as a means to select administrators.

By the end of the Song dynasty non-noble clans were already common. The transition is reflected in a data set we compiled containing information on 5,083 genealogies - a $10 \%$ sample of the largest collection of clan genealogies (Wang, 2008). ${ }^{15}$ About half of this sample

\footnotetext{
${ }^{14}$ Although lineages and kinship groups were active and important, they had distinct, usually social, character. See, for example, Zhenman (1992), p. 191.

${ }^{15}$ Wang published basic information about each surviving genealogy. The factors influencing survival are unclear and the data should be accordingly analyzed. We are extremely grateful to to George Zhijian Qiao (Stanford University) and Prof. Hongzhong Yan (chair of the economic history department in Shanghai University of Finance and Economics) for creating this dataset for this study.
} 
records the dynasty during which the clan's founder lived. According to this measure, the large majority of clans (82\%) originated during and after the Song dynasty (960 - 1279). The Song dynasty is also the period during which the largest number of clans originated in both absolute and per-year terms (35\% and 2.6 clans-per-year). The Tang dynasty (618 906) follows (with 22\%), but in terms of genealogies per-year the Yuan dynasty (1279-1368) was ahead (2 clans per-year vs. 1.8). ${ }^{16}$

Turning to Europe, large kinship groups, particularly tribes, were also historically important and were strengthened by the immigration of Germanic and other tribes following the collapse of the Roman Empire (Maine, 1999 [1861]). Under the medieval Germanic laws, kin were obliged to assist each other in seeking justice (Drew, 1991, p. 40). In sixth century Salic (Germanic) law, membership in a large kinship group was necessary for various legal rights. The 6th century Salian Franks legal code went further to render relatives mutually liable for debts, legal penalties, and legal compensations (ibid). This was no longer the case in the 10th century. By then, at least in the English code of law that survived, neighbors, not relatives held such responsibility. Similar change seems to have transpired on the continent as well. By the 8th century the term family among the Germanic tribes denoted one's immediate family. ${ }^{17}$ Tribes and lineages, by and large, were no longer institutionally relevant (Guichard and Cuvillier, 1996). ${ }^{18}$

The concept of corporation was developed during the Roman period and was regulated by the Roman law. Establishing corporations, however, required the consent of the Emperor and was mainly used by the state in the pursuit of its interest. In other words, the corporation was not an important social organization during the Roman period. It was only in the late medieval period that corporations became a common form of social organization. The main reason for their emergence was not the precedents set in the Roman period per-se, but the limited capacity of the state and the papacy to meet the evolving needs to provide local public goods by the late 9th century (Greif, 2006, 2006a).

The focality of the corporations was fostered when the Papacy incorporated itself. During the eleventh century, the Church became a corporation to deflect threats to its independence and property from secular rulers and the Church's agents. To this end, the papacy formu-

\footnotetext{
${ }^{16}$ We don't know the years in which the ancestor lived. It is probable that the clans emerged in the late Tang when land was no longer distributed to newly formed families. Moreover, because pre-Song clans were aristocratic, later clans might have misrepresented the dynasty of origin to link the clan to an ancient aristocratic one. Be it as it may, the clans during the Tang Dynasty were a localized phenomena. Only 3.1\% of the clan that originated during the Tang Dynasty had moved to another province during that dynasty. In contrast, $29 \%$ of the clans that originated during the Song immigrated to another province during that time. Moreover, of the 3521 clans that move from one province to another only $4.7 \%$ moved during the Tang and $27.5 \%$ moved during the Song.

${ }^{17}$ Clearly, the European family did not evolve monotonically toward the nuclear family, nor was its evolution geographically and socially uniform.

${ }^{18}$ Quantitative evidence from Europe reveals that when the clans were proliferating in China, kinship groups were marginal in Europe. Cousins, judging from testimonies in English court rolls from the 13th century, were not more likely than non-kin to be in each other's presence (Razi, 1993). In 1377, there were approximately 2.3 individuals over the age of thirteen per-household (Schofield, 2003, p. 83). The mean household size in five English parishes in the 16th century ranged from 4.05 to 6.05 and that of 100 parishes from the 16th to the 19th century was 4.788. Only about $10 \%$ of the households had a resident kin (Laslett, 1969 , pp. 204, 207, 218). The mean household size of those receiving poor relief in Strasbourg in 1523 was similar (Jutte, 1996, p. 382).
} 
lated a corporate law that drew on Roman, Germanic and Christian legal principles. It rejected the view that royal permission was required to establish a corporation, asserted that any corporation has the right to tax its members over whom it also has legislative and judicial jurisdiction, and placed a corporation's agents under the authority of its members. (Berman, 1983). This codification bestowed legitimacy on self-organized and self-governed corporations in general, created a related moral code and coordinated expectations. Similarly, the emerging European states promoted corporations to foster their administrative capacity in competing with each other and the papacy (Greif, 2008).

By the late medieval period, the corporation had become the dominant social organization in Europe. To illustrate the broad reach of the corporations note that in the 14th century the majority of the English urban population belonged to various fraternities and guilds (Richardson, 2004; Ashely, 1888; Sommerville, 1993). Self-governed cities proliferated in Europe at the time. In England 268 cities were incorporated by a charter between 1042 and 1307 and their number subsequently rose to almost 500 (See figure 2). ${ }^{19}$

$<<$ Insert figure $2>$

Figure 2: Incorporation of English Cities

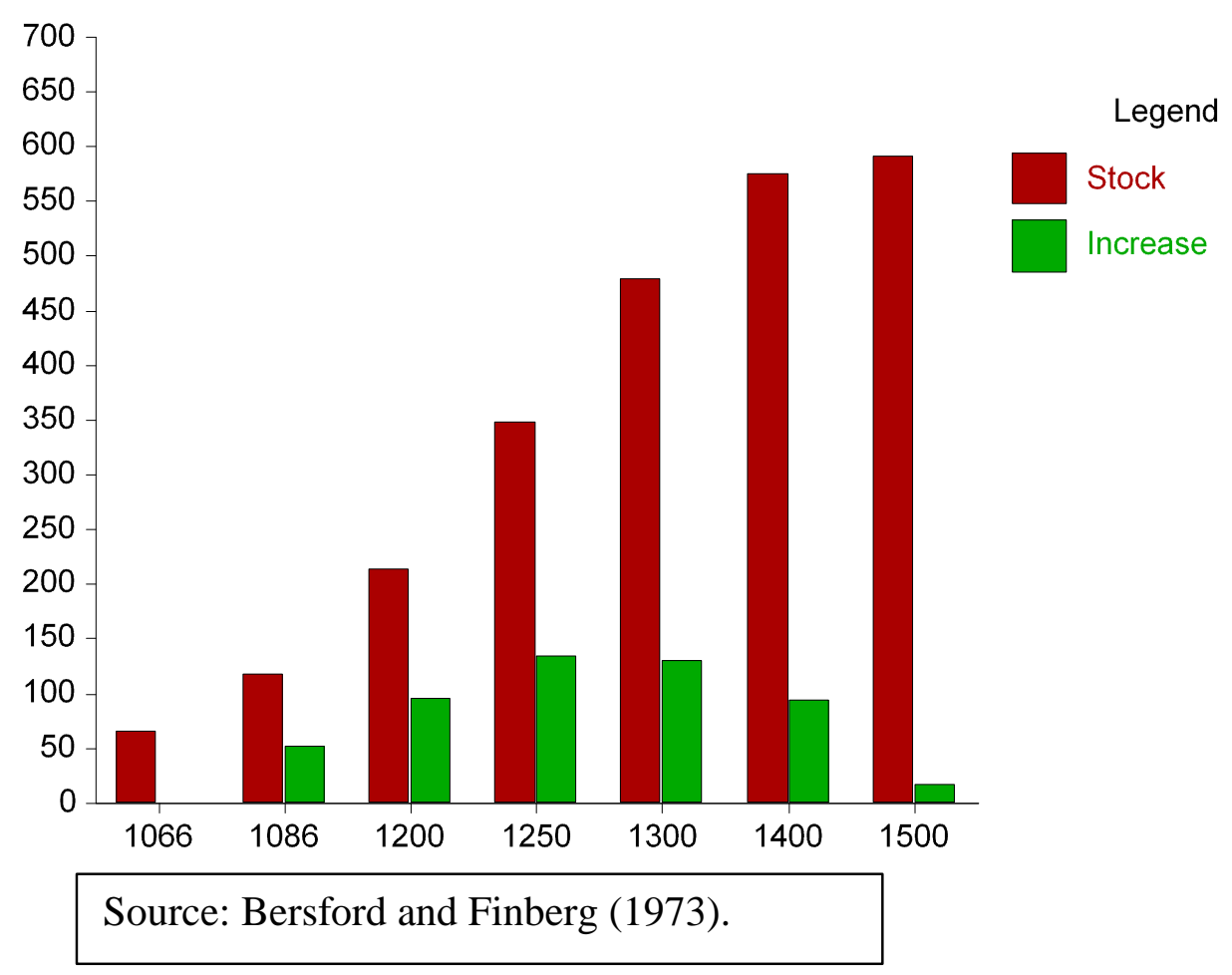

\footnotetext{
${ }^{19}$ Ballard (1913); Ballard and Tait (1923); Beresford and Finberg (1973). In Germany 2,256 incorporated cities were created by the 17th century $<<$ http://en.wikipedia.org/wiki/ List_of_towns_with_German_town_law >>, Cantoni and Yuchtman (2014).
} 
Corporate bodies were also pervasive in the European countryside. More than 40 percent of the English population belonged to a self-help Friendly Society in the early 19th century (Greif and Iyigun, 2013). Pre-modern European peasantry in general was largely organized in corporations (Reynolds, 1984, chapters 4-5; Brenner, 1987). The monastic, self-governed order of Cluny alone had, by the 12th century, 2000 affiliated monasteries in France alone (Davis, 1961, pp. 35-87). The Cistercians order, dedicated to work and prayer, grew by the 13th century to have about 600 monasteries throughout Europe, from Ireland to Poland. Universities, Abbeys, and Cathedrals were corporations as well. Urban and rural settlements were similarly corporations.

Despite variations in time and details, a similar development transpired in other part of Europe as well. Most European cities west of the Baltic Sea in the north and the Adriatic Sea in the south were incorporated (Pirenne, 1974, pp. 168-212; Cantoni and Yuchtman, 2014). Germany had, in 1422, at least 75 cities recognized by the Emperor as 'free' and by 1521 their number increased to 84 while the Hanseatic League included about 190 self-governed German cities (Dollinger, 1970, p. 116). In Flanders, a 12th century urban law recognized its cities' self-governance (Nicholas, 1992, pp. 119-23). About 20 percent of the population of Castile in 1500 lived in its 30 self-governed cities and 60 percent lived in villages which were self-governed although subject to a lord (Nader, 1990, p. 3).

Clans and corporations were common, in China and Europe, in both the rural and urban sectors. Yet, our model implies that urbanization - particularly in cities that were not created by the state authorities - would be higher in Europe, while China would have smaller urban centers dominated by clans. This indeed was the case. The share of the population living in cities with more than 10 or 40 thousand people was higher in Europe than in China (Figure 3).This observation is even more striking given that in the 10th century or thereabout, China was more urbanized than Europe. Urbanization in Europe increased following the dissolution of the large kinship groups. In China, large administrative cities were created by the state, while small market towns were created by clans to consolidate their local control (at least since the Ming dynasty).

$$
<<\text { Figure } 3 \text { around here }>>^{20}
$$

Figure 3: Urbanization in China and Europe

\begin{tabular}{|c|c|c|c|c|}
\hline & \multicolumn{2}{|c|}{ Europe } & China & \multicolumn{2}{c|}{ Europe } & \multicolumn{1}{c|}{ China } \\
\hline & \multicolumn{2}{|c|}{$>$ 10k } & \multicolumn{2}{|c|}{$>$ 40k } \\
\hline $\mathbf{1 0 0 0}$ & 0 & 3.1 & na & na \\
\hline $\mathbf{1 5 0 0}$ & 5.6 & 3.8 & 1.9 & na \\
\hline $\mathbf{1 6 0 0}$ & 7.6 & 4 & 3.5 & 1.7 \\
\hline $\mathbf{1 7 0 0}$ & 9.2 & na & 5.2 & 1.9 \\
\hline $\mathbf{1 8 0 0}$ & 10 & 3.8 & 5.6 & 1.7 \\
\hline
\end{tabular}

\footnotetext{
${ }^{20}$ Other estimates, such as Rozman (1973) and Brandt et al. (2013) qualitatively differ but qualitatively concurs with the estimates presented here. Rozman calculated an urbanization rate of 4.7 in mid Tang, 5.2 in mid Song, 6.5 in mid Ming, 6.8 in early Qing, and 5.9 in late Qing. See Maddison (1998), p. 35.
} 


\subsubsection{Migration and the choice of social organizations}

The model builds on the idea that social organizations evolve out of a bottom-up process, in which individuals choose which organizations to join, based on convenience and cultural affinity. This idea is consistent with how social structures emerged in China and Europe during and after the 10th century when states were weak or non-existent, and a large resettlement of population took place in both regions. Migration, together with a vacuum in the provision of basic public goods, created a unique opportunity for a bottom-up process of social and cultural evolution. In both regions, individual-level choices regarding whether to immigrate and with whom shaped the evolution of social organizations.

In China, migration from the wheat-producing North was due to an adverse climatic shock and invasions from central Asia. Both factors contributed to a large migration of Han people from the North to the East and the South (e.g., Kuhn, 2009, chapter 4). In Europe, large-scale migration transpired as forests were cleared and areas previously inhabited by Slavs and Muslims were resettled.

In both regions, the migration process took place in the context of weak central authorities (either political or religious). In China, the Song dynasty stronghold was in the North while the migrants moved to the East and the South where the state was relatively weaker. In Europe, the Carolingian empire disintegrated in the 9th century while the Papacy was defacto captured by the Roman nobility. Neither the state nor the Papacy had an effective administration capable of providing local public goods (e.g., Greif, 2006a).

In both China and Europe, individuals could migrate and settle in the company of their kin or with non-kin. Yet, the responses in China and Europe differed. China settlement was "based on kinship ties" and migrants "constructed a new kin-group on the frontier for the purpose of land clearance and developing an irrigation infrastructure" (Rowe, 2002, p. 534). ${ }^{21} \mathrm{~A}$ similar pattern of kin-migration also transpired in later periods when population moved to repopulate regions devastated by natural and man-made disasters.

The distribution of genealogies in China reveals the role of migration in the diffusion of the clan system. This claim is based on a data set of about 1000 genealogies that Telford (1986) collected and analyzed. ${ }^{22}$ In particular, Telford examined the content of the genealogies to identify exactly when the clan became a social organization and not a collection of individuals with common ancestry (a dynasty). The temporal and spatial distributions of this information is therefore a good proxy of the distribution of clans.

The data presented in figure 4 reveals that clans first emerged in the east and south - areas that attracted migration during the Song (960-1279) — and not in the north, the birthplace of the Han people that during this period were out-migrating to the East and South. The figure presents the percentage of each region's genealogies - records of a clan's

\footnotetext{
${ }^{21}$ The arguement that immigration was a primary factor in the initial process of clan formation goes back at least to Burton Pasternak (1966) and Emily Ahern (1976). Other scholars noted how the clan system was reinforced by its use by the state and elite to perpetuate their control. The system was thus reinforced, as noted below, by various institutional features, such as the examination system (e.g., Szonyi, 2002). The subsequent functions of the clan system, however, do not explain its origin.

${ }^{22}$ The limitations of Telford's data are many. The sampling process is not reported and, as Telford noted, which genealogies survived and why is unclear. Moreover, we do not know whether a clan's first ancestor is fictional or real. Our data set on genealogies specifies when a clan's founder lived, while Telford dates the origin of the clan based on features of the genealogy itself.
} 
members - that trace the clan's origin to a given period. Thus, for example, about 40 percent of the sample genealogies from the East trace the clan's origin to a year prior to 1644. The data thus suggests that prior to 1368, clans prevailed in the East and South. They emerged in the North and West only by the Ming period. This period witnessed a large migration back to the North and West, following depopulation due to the Yuan-Ming and the MingQing wars and the latter period's Westward expansion. These inter-regional differences in genealogies do not seem to reflect differences in population density as the regional shares of clans and population grew closer over time (see Heijdra, 1998, p. 440).

$$
<<\text { Insert figure } 4>>
$$

Figure 4: Percentage of Regional Genealogies Tracing the Clan's Origin to a Given Period

\begin{tabular}{|c|c|c|c|c|c|c|}
\hline Years & to 960 & 960-1279 & 1279-1368 & 1368 - 1644 & 1644-1911 & 1911-1949 \\
\hline Period & & Song & Yuan & Ming & Qing & Republic \\
\hline East & 0.01 & 0.02 & 0.11 & 0.4 & 0.24 & 0.22 \\
\hline South & & 0.05 & 0.04 & 0.3 & 0.47 & 0.14 \\
\hline West & & & & 0.14 & 0.73 & 0.13 \\
\hline North & & & & 0.14 & 0.34 & 0.52 \\
\hline \multicolumn{7}{|c|}{ Source: Telford, 1986, table 10.} \\
\hline \multicolumn{7}{|c|}{ Clan distribution is proxied by (1002) genealogies. We thank Carol H. Shiue for bringing this data } \\
\hline \multicolumn{7}{|c|}{ to our attention.. North: Hebei, Jilin, Liaoning, Shanxi. East: Anhui, Fujian, Jiangsu, Shandong, } \\
\hline \multicolumn{7}{|c|}{ Zhejiang. South: Guangxi, Henan, Hubei, Hunan, Shaanxi. West: Guangdong, Guizhou, Jiangxi, } \\
\hline \multicolumn{2}{|c|}{ Sichuan and Yunnan. } & & & & & \\
\hline
\end{tabular}

The spatial distribution of these genealogies reveals that clans were common in all Chinese provinces (figure 5, upper panel), although most of them are from the East and South (lower left panel). Taking into account regional population share reveals a more even distribution of clans over provinces. Around 1578, the regional distribution of the genealogies roughly corresponds to the regional population share (lower right panel). ${ }^{23}$ It is reassuring that similar results are obtained from our $10 \%$ sample of all the surviving genealogies. ${ }^{24}$

$$
<<\text { Insert figure } 5>>
$$

While kinship was the basis for the Chinese settlement process, cooperation among individuals unrelated by blood was the hallmark of the rapid process of urbanization in Europe. To illustrate, the earliest ancient Venetian public document enabling the study of family structure is from 1090. It concerns a gift from the Byzantine emperor to a local monastery. The 127 individuals mentioned in the document have 91 different last names (Folena, 19701). Later documents containing the lists of the people elected to the Great Council from 1261 to 1296-7 has names of 392 individuals with 119 last names (ibid). In Genoa, 136 families

\footnotetext{
${ }^{23}$ Similarly, the 151 clan rules from 1912 and 1936 that were preserved in the University of Columbia library, are from throughout China (Liu, 1959, p. 13).

${ }^{24}$ The results are available upon request.
} 
Figure 5: Clan Distribution Over Time and Provinces
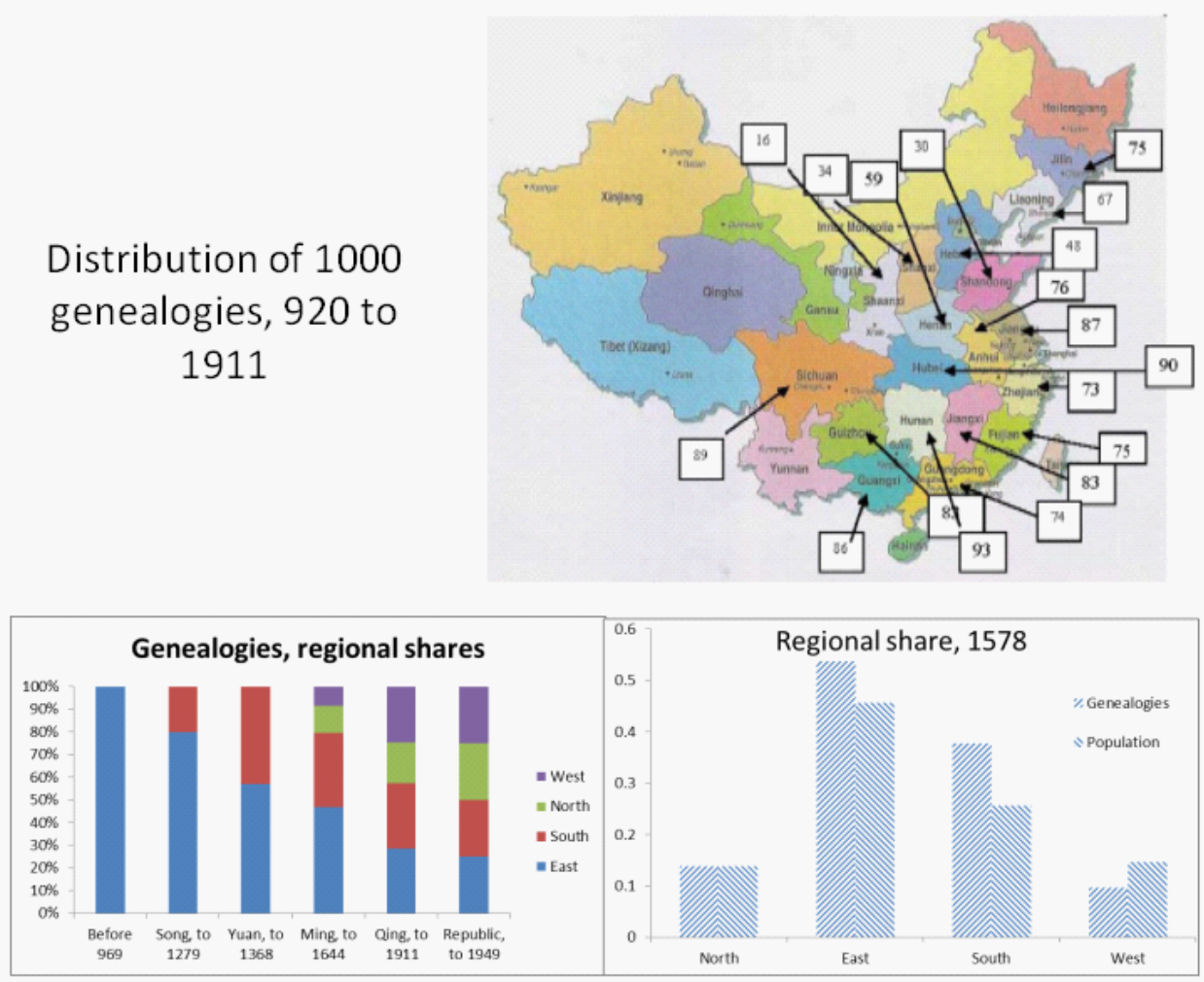

constituted the top mercantile non-aristocratic merchants from 1375 to 1450 (Van Doosselaere, 2009, Appendix E). In 1541 London, only 7.85 percent of the population of London had the top most common 10 last names. Low concentration of last name, more generally, is evident from the 356,834 English marriage certificates in the Vicar-General Marriage License Index (1694 to 1826). There are 52,872 different last names in the index. ${ }^{25}$

More generally, European rural and urban corporations, unlike the Chinese clans, were not kin-based. Consider, for example, the distribution of last names in English towns according to the 1881 English census. The mean proportion of the population with the most common surname was 0.079 and the mean proportion of the most common 10 surnames was 0.39. If, in each county, we ommit the town with the most common surname. The mean proportion of the population with the most common surname was is a mere .018. Moreover, because many individuals unrelated by blood have the same surname, the actual concentration of families is much lower. The surname Smith, for example, was the most common surname in 30 of the 39 English counties (in 1881). ${ }^{26}$

Comparing the early modern migration of Chinese and Europeans reveals that, as predicted in our model, Chinese immigrants did not integrate into the city after moving there, but they continued to provide public goods to their kin rather than to the local, non-kin

\footnotetext{
${ }^{25}$ London: http://www.ellipsis.cx/ liana/names/ english/engsurlondon1541.html (Index of Names in the 1541 Subsidy Roll of London: Surnames of English men and women by Sara L. Uckelman. 05Agu06.) English marriage: http://www.sog. org.uk/vg/vgstats.htm.

${ }^{26}$ Calculated from the 1881 Population Census. http://www.britishsurnames.co.uk/1881census/
} 
populations. Clearly, both Chinese and European immigrants remained attached to those left behind. They sent remittance back home and often financed migration by relatives.

Yet, the two groups differed in an informative way. Chinese migrants went beyond sending money to relatives; they also sent money to provide local public goods in their place of origin. Such contributions were rare among European migrants. Chinese migrants also aspired for burial in their place of origin and not their place of settlement. Attachment to the place of origin also characterized migration within China, as migrants retained their affiliation with their rural kinship groups. As late as the 17th century, in a relatively new city, "the majority of a city's population consisted of so-called sojourners, people who had come from elsewhere and were considered (and thought of themselves as) only temporary residents .... Suspicions were always rife that sojourners could not be trusted" (Friedmann, 2007, p. 274). More generally, families that moved to cities retained "their allegiance to the ancestral hall for many generations, the bonds of kinship being much closer than those of common residence" (Hu,1948, p. 10). This outcome corresponds to the intuitive implication of our model that clannish type who are sufficiently loyal to the clan would contribute to the clan even after moving to the city for economic reasons.

\subsection{Morality and kinship groups}

According to the theory of section 3, different social organizations emerged in China and Europe because these two societies had initially different cultural traits. Moreover, these cultural differences became more pronounced over time, as a result of the mutual reinforcement of culture and social organizations. Is this coevolution of morality and social organizations consistent with the historical evidence? This subsection argues that it is. Around the turn of the millennium, when clans and corporations began to spread in China and Europe respectively, notions of morality and loyalty groups were already different in these two societies, and these differences became more pronounced over time.

Past social organizations are often well reflected in historical records such as genealogies, clan regulations, charters, and city-rolls. Morality, in contrast, is inherently unobservable and usually leaves behind much more subtle evidence. We rely on three sets of indirect historical evidence regarding morality: religion, the criminal law, and voluntary charity.

\subsubsection{Religion}

Different religious beliefs are perhaps the most evident manifestation of different initial moralities in the distant history of China and Europe. The idea of universal moral obligations was an important component of European culture at least from the Roman period. Building on an earlier Greek and Jewish traditions, Christianity promoted the creation of "a new society based not on the family but on the individual, whose salvation, like his original loss of innocence, was personal and private" (Hughes, 1974, p. 61). The New Testament identified moral obligations toward non-kin with following the divine law. "He who loves his neighbor has fulfilled the law" (Romans 13:8) and the most prominent Christian theologians and philosophers built on this idea. For example, St. Augustine of Hippo (354-430) argued

that one has to seek salvation through the divine law through which one gains grace, while 
by the 13th century St. Thomas Aquinas asserted that only moral law which is consistent with the divine law is just.

When the tribally organized Germanic people overtook the Roman Empire, limited morality became more prominent. This lasted only a few centuries, however, and by the end of the first millennium large kinship groups (among commoners) were socially, economically, and politically important only on the European geographical margins such as Scotland and Italy.

The decline of extended kinship relations was probably due to the influence of the Church that encompassed all of Europe with XIth century conversion of the last European pagans groups (e.g., Scandinavians, Basques, and Hungarians). The Church's marriage dogma had an important role in the decline of large kinship groups as it discouraged practices that enlarged the family, such as adoption, polygamy, concubinage, easy divorce, and remarriage. In particular, the dogma curtailed practices through which kinship perpetuated such as kin marriages and de-facto unlimited parental control over marriages. ${ }^{27}$

The principle of universal morality in Christian religion contrasts with the emphasis on moral obligations towards kin in Confucianism. Confucius (551 - 479 BCE) argued that one has the moral obligation to protect kin, even one who broke the law and harmed others. To illustrate, Confucius' Analects contains an exchange between Confucius and a governor representing the Chinese philosophical tradition that stresses the law as the basis of political organization. This tradition associated morality with legal obedience. "The Governor ... said to Confucius, "in our village there is a man... when his father stole a sheep, he gave evidence against him.' Confucius answered 'In our village those who are straight are quite different. Fathers cover up for their sons, and sons cover up for their father. Straightness is to be found in such behavior" (Analects, XIII, 18).

These traditional Chinese features were undermined during the first millennium by the advance of Buddhism, but not for long. Pre-Song Buddhism emphasized individualistic salvation, the community of believers, and spirituality. The Tang Dynasty, however, limited the expansion of Buddhism in China, probably for political and fiscal reasons. The Song dynasty went further in supporting Neo-Confucianism, and Buddhism responded by also promoting obligations to kin. As a result, post-Song Chinese Buddhism also subscribes to the kinship based Confucian social organization and morality.

\subsubsection{Criminal law}

The punishments imposed on criminal offenses reveal morality because crime, by definition, is immoral and its underlying principle is that the punishment should fit the crime. Comparing the nature and dynamic of criminal punishments in China and Europe reveals distinct cultural evolutions. Initially, punishments on criminal offenses in both regions depended on the identity of those involved. Subsequently, however, punishments in Europe became increasingly independent from identity, at least de jure. In China identity became more important over time.

The temporary surge and then decline in moral obligations to kin in Europe is clear from legal codes. Consider the earliest Germanic legal code of the Salian Franks (6th century).

\footnotetext{
${ }^{27}$ E.g., Mitterauer et al. (1982); Goody (1983); Ekelund et al. (1996); Herlihy (1985); Greif (2006), chapter 8, and Greif (2006a).
} 
The code imposes "blood money" on a killer of another person. A killer of a (free) Frankish man or a woman was to pay 200 solidi to the victim's relative as compensation. If the crime was committed toward a public official, the penalty was higher reaching as much as 1,800 solidi if the victim was serving in the army. The highest blood money for killing a GalloRoman, however, was generally half of the amount imposed for killing a Frankish person (Drew, 1991, pp. 45-9).

In subsequent centuries, however, the theory and practice of criminal law drastically changed. Late medieval legal writers in England, Germany, and France emphasized the "principle [that] all human beings are equal" (Kelly, 2003, pp. 146-7). Moreover, the "communities that had a strong sense of the individual's responsibility and his citizenship or membership" objected to "trial by battle and by ordeal" (Kelly, 2003, pp. 147-8).

The punishmensts specified in European criminal codes did not depend on whether the parties involved were kin. This is most evident in communal laws, which were based on the principle of equality before the law and reflected generalized morality. To illustrate, consider the 14th century statute of the Piedmontese commune of Bugelle (Biella). The statute declares that "the consuls can and should render justice and a fair reckoning in respect to each man of Biella, each person residing in Biella, and any one who seeks justice from them" (Sella, 1904, sect. 1.2). The same principle prevailed in England at that period. The judges in Exeter and Southampton took an oath to "render justice indifferently to rich and poor.. [and] to do and keep justice to all persons, rich and poor, denizens and strangers" (Tait, 1936, p. 275). By the 17th century, the criminal law imposed a higher penalty on the rich for the same crime to equalize the severity of the punishment (Kelly, 2003, pp. 238-9).

In contrast, under the late Imperial Chinese law, punishments depended on kinship. Generally, penalties were most severe for crimes committed against senior relatives, less severe if committed against those outside of the extended family, and least severe if committed by senior family members against their younger kin. Even in "the early twentieth century, a father could kill his son without incurring much more than a reproof and a warning, while a son who killed his father, or even his only slightly older brother, faced a very hard time. Only the killing of friend by friend came to court on an even keel, so to speak" (Gellhorn, 1987, p. 2).

\subsubsection{Charity}

Whether charity - private contributions to assist others - is personal or impersonal is a good measure of moral obligations toward non-kin. Charity is personal when the giver donates to specific individuals he knows and it is impersonal otherwise. If limited morality was more important in China relative to Europe, personal charity among kin was more likely to predominate. In contrast, if generalized morality was common in Europe, impersonal charity to non-kin was more likely to predominate. This, indeed, was the case.

In pre-modern China, kin were the main source of charity either through clan-trusts or local temples (as was particularly common in multi-clan villages). The moral aspect of this practice is clear from the discussion of Fan Chung-yen (989-1052), the innovator of the clan trust. Fan "had ruled that the lineage should aid only relatives with lineage ties that were clearly documented in the genealogy" (Smith, 1987, p. 316). This had became the norm for hundreds of years. Permanent, non-Buddhist, impersonal charity organizations appeared, 
on some scale, only in the early 17th century. In surveying the evidence, Smith noted that "the first documented benevolent society appeared in ... Honan, in 1590" (p. 311) and concluded that only "during the late Ming (1368-1644) and early Qing (1580-1750) ... [new organizations were created] to voluntary or compassionate giving to the poor and needy outside one's family" (1987, pp. 319-21).

Although the Chinese authorities encouraged impersonal charity, moral philosophers asserted that the diversion of assistance away from kin is immoral. A popular 17th century morality book "tells of a generous scholar who was derided by a member of his lineage for lightly giving money away to strangers" as a charity (Smith, 1987, p. 316). Even so, clans remained the main source of poverty alleviation. This limited morality logic confused pre-modern European observers. In 1851, the English economist John Ramsay McCulloch pondered the contradiction he saw between destitutions and generosity toward the poor. In his words, "the conditions of the poor are wretched in the extreme; they are frequently destitute of food... It is a curious fact, that though the Chinese be remarkable for assisting each other, particularly their own relations" (vol. 1, p. 361).

Early 20th century clan-rules (1912 - 36) reveal the persistence of the kin-based welfare system. The largest collection of Chinese genealogies in the US (at Columbia University) has 151 clan-rules, some of which are from previous centuries. These are considered representative of the traditional clan rules (Liu, 1959) and half of them (75/151) contain sections concerning clan relief and aid of needy members (ibid, p. 217). Another piece of evidence for the extent of personal charity is found in the seminal 1925 study of country life in South China. The study notes that the poor "depend largely upon the aid granted them by the village leaders from the income of the public property and upon the surplus over the cost of worship when they rotatively administer ancestral property" (Kulp, 1925, p. 104). ${ }^{28}$ Similarly, the prominent Chinese historian of common decent groups Hsien-Chin Hu, noted that on the eve of Communist era clans were still prominent providers of welfare assistance to their members (1948, pp. 87-90).

In Europe, impersonal voluntary charity was common from the early days of the Catholic Church. By the 16th century, organizations providing impersonal private charity predominated. To illustrate, London in 1560 had about 35 poor relief-foundations and by 1700 there were more than 100 of them. In late 16th century Bristol, quarter of the wills made a donation for the "relief of the poor" while a century later 30 percent of the will in England made such donation (Ben-Amos, 2000). The French poor relief system, among others in Europe, was supervised by the state but was financed mainly by voluntary contributions.

Summarizing, the religions prevailing in China and Europe towards the end of the first millennium created different initial conditions. Moral obligations towards kin were stronger in China, while Christianity created a cultural predisposition towards generalized morality in Europe. These cultural differences manifested themselves in salient features of these societies such as the criminal code and charity. These distinctions became more pronounced overtime, together with the diffusion and consolidation of different social organizations, as implied by the theory.

\footnotetext{
${ }^{28}$ Public property was "owned collectively by the sib-group" (Kulp, 1925, p. 123).
} 


\subsection{Complementary institutions}

Social organizations such as the clan and the corporation interact with market and state institutions. This subsection discusses how these institutions further reveal the importance of the cultural and social bifurcation between China and Europe and how they created additional reinforcing effects that accentuated it.

\subsubsection{Market institutions}

Pre-modern markets in China and Europe were based on institutions that complemented the clan and the corporation. These complementary institutions and the resulting market interactions reinforced the underlying social and cultural foundations.

The comparative development of markets in China and Europe is puzzling if one ignores their distinct social organizations. On the one hand, the Chinese and European markets were similarly integrated on the eve of the 19th century (Shiue and Keller, 2007). On the other hand, European markets increasingly supported more impersonal exchange, particularly in financial markets. While credit and insurance instruments were widely used and traded in Europe from the late medieval period, this was not the case in China where the first credit institutions emerged in the 18th century. ${ }^{29}$ This distinction was known at least as early as 1851, when the English economist John Ramsay McCulloch noted that "credit is little known" in China (vol. 1, p. 628). In short, markets in China and Europe were similarly integrated but supported impersonal exchange to a different extent (Greif, 2005). The conjecture that cooperation in China and Europe was based on clans and corporations, however, provides a consistent explanation to both phenomena.

In Europe, corporations composed of non-kin and generalized morality provided the social and cultural foundations for institutions that supported impersonal exchange since the late medieval period. One early institution incentivized local public officials to dispense impartial justice to alien merchants. ${ }^{30}$ This institution enabled a trader from one community to undertake contractual obligations toward a member of other communities even if their relations were not expect to repeated in the future even under limited information about past conduct and performance. ${ }^{31}$ This institution, the Community Responsibility System (CRS), motivated the inherently biased local courts and other dispensers of justice to punish members of their community who reneged on their inter-communal contractual obligations.

Under the CRS, courts held all members of a different commune legally liable for every member's defaults on contracts with a member of the local commune. If the defaulter's communal court refused to compensate the injured party, the latter's communal court imposed cost on the defaulter's community by, for example, distraining the property of any member of the defaulter's commune present in its jurisdiction as compensation. A commune could avoid compensating for the default of one of its members only by ceasing to trade

\footnotetext{
${ }^{29}$ Regarding Europe see Trenerry (1926), de Roover (1945), and Postan (1928). Regarding China see Kuroda (2013) and Mann and Kuhn (2008), p. 109.

${ }^{30}$ See Greif (2005), (2006), and (2006b). For other institutions, see, for example, Gelderblum (2011), Gelderblom (2013), Strum (2013), and Kessler (2007).

${ }^{31}$ The medieval commune has many attributes of a state (e.g., formal courts and ability to impose legal sanctions) but differed from the modern notion of the state in the sense that the incentives to the judges were provided by the commune and not by an exogenous state.
} 
with the other commune. When this cost was too high, a commune court's best response was to dispense impartial justice to nonmembers who had been cheated by a member of the commune. Expecting ex post dispensation of impartial justice, traders were motivated to enter into impersonal, intercommunity exchange. Intercommunity impersonal exchange was possible, not despite the partiality of the court, but because of it; the court cared about the community's collective reputation (Greif, 2006a, 2006).

To illustrate the historical importance of the CRS, consider a charter granted to London in the early 1130s. King Henry I announced that "all debtors to the citizens of London discharge these debts, or prove in London that they do not owe them; and if they refuse either to pay or to come and make such proof, then the citizens to whom the debts are due may take pledges within the city either from the borough or from the village or from the county in which the debtor lives" (English Historical Documents, vol. II: 1012-3, see discussion by Stubbs, 1913).

This charter is representative; evidence from other charters, treaties, and regulations reveals that the CRS was the law of the land in England. Charters for English towns reveal that by 1256 cities that were home to 65 percent of the urban population had clauses in their charters allowing for and regulating "distrain" (impounding) of goods under the CRS. The centrality of the CRS in supporting English trade among members of various towns is also revealed in the surviving correspondence of the mayor of London for the years 132433. In this correspondence, 59 of the 139 letters dealing with economic issues (42 percent) explicitly mention community responsibility. They indicate that the mayor was motivated and expected the authorities of other towns to be motivated by the threat that all members of a community would be held liable if certain actions were not taken (Greif, 2006a, 2006). The CRS implied de-facto equality before the law. Similarly, equal legal treatment of out-oftown traders was generally mandated in European cities' and had a positive and significant impact on trade (Boerner and Quint, 2010).

The CRS took advantage of repeated inter-communal relations to support non-repeated relations among their constituting members. One would expect that a similar institution can, in principle, be used in inter-clan relations. This was indeed the case with respect to various aspects of inter-clan relations. Clan regulations in general specified that "a clan should always watch its reputation by preventing its members form harming outsiders and by refusing its offenders clan protection" (Liu, 1959, pp. 152). At the same time, the moral obligation to kin seems to have limited the credibility and effectiveness of intra-clan punishment for inter-clan transgression. "The punishment of a member who misbehaves against a non-clan member is usually oral censure" while "the punishment for siding with outsiders in an aggression against fellow clan members is, however, much more severe.... the group interest is placed higher than [inter-clan] community solidarity" (ibid).

More generally, limited morality reduces the cost of intra-group relations relative to inter-group relations. Less inter-group relations, in turn, reduces the return from investing in legal enforcement and undermines alternative, reputation-based institutions such as the CRS that requires a sufficiently high present value of expected inter-group future relations. In contrast, under generalized morality the set of relations that have to rely on legal enforcement is the same in intra- and inter-group relations. Compared to the case of limited morality, generalized morality leads to more inter-group exchange relations (everything else being equal) and thus complements inter-group enforcement institutions. 
It is reassuring to find that, consistent with this analysis, intra-clan commercial networks were important in long distance trade in China. In these networks, limited morality and institutions based on repeated interactions supported cooperation. To illustrate, "the sprawling merchant diaspores that managed 18th century interregional trade usually were built upon kinship ties. The huge shipments of rice ... were overseen by groups of Kiangsi merchants organized internally by lineage" (Rowe, 2002, pp. 531-2; Ma, 2004). ${ }^{32}$ It is reasonable to postulate that intra-clan exchange reinforced limited morality. In fact, Chinese clans' rules from the 20th century often state that "one must be very careful about" friendship with strangers (Liu, 1959, p. 148). About 95 percent of clan rule books call for care in selecting friends while only 8 percent call for "helping a friend in trouble" (ibid).

The impact of limited morality on economic institutions is reflected in their extensive reliance on personal relations. Investments specific to the relations compensated for the absence of generalized trusts. For example, clans from one locality cooperated to advance their common interests in other locations. Similarly, in the trading and late settlement frontiers in the North and Taiwan, temple-based associations were established as a means to substitute for the absence of strong clans. Investments in relations, and joining a particular group, fostered reputation mechanisms as a substitute for both general moral obligations and legal enforcement.

Advanced payment and guarantees were among the other institutionalized mechanisms widely used in China to facilitate trade among non-kin. "A trader in grain or goods conventionally made a large advance payment - sometimes as much as eighty percent of the agreed price - when placing the order. A later default in payment was therefore considerably less agonizing to the seller than otherwise it would have been. Disputes about the quality of what had been purchased rarely arose because, by commercial custom and private agreement (..), the purchaser was expected to inspect carefully and to decline acceptance of anything found to be unsatisfactory. If acceptance did occur, the buyer was barred from later complaining that he had not received what he had been promised" (Gellhorn, 1987, p. 3). Despite these measures, however, market expansion was limited in China. "Despite China's expanse, trade was largely local, the disputants lived in the next lane, the brother of one of them had married a sister of the other, and neighborly mediation was readily accepted because, after all, everyone involved in the controversy was going to have to go on living with everyone else after the present disagreement had been smoothed over" (Gellhorn, 1987, p. 3).

The social and cultural distinctions between China and Europe grew larger over time, as our evolutionary approach implies, also through feedback effects from market institutions to their social and cultural underpinnings. For example, in Europe the Community Responsibility System implied equality before the law, thereby reinforcing generalized morality. It also motivated members of a commune to promote generalized morality in their ranks, because outsiders held each of them liable for misconduct by another member. Similarly, personal exchange in clan-based commercial networks probably reinforced limited morality.

\footnotetext{
${ }^{32}$ For morality in overseas Chinese trading networks see, e.g., Landa (1981), Pyatt and Redding (2000), and Redding (1993).
} 


\subsubsection{State institutions}

If the clan and the corporation had significant advantages in enforcing cooperation, one would expect that the states in both regions would try harness this capacity for their advantage. State institutions - particularly its administration - should have evolved to complement the prevailing social organizations. Here we substantiate that this was historically the case. The administration of states in China and Europe complemented and coevolved with the corresponding social organizations. In other words, the states' administrative structures exploited the social and cultural foundations that enforced cooperation at the local level.

Clans, cities and states' administration. Chen Hongmou (1696-1771) was among the many pre-modern policy-makers in China who recognized the importance of incorporating the clans in the state institutions. Chen was a high-ranking official, a scholar and a philosopher who was held as a model provincial governor during the Qing dynasty. Chen explicitly advocated relying on clans to reduce the size of government. As a governor in 1742, he granted lineage headmen considerable judicial and disciplinary powers over their kinsmen (Rowe, 1998, p. 378). More, generally, Chen "consistently supported the principle of lineage organization. He relied, for example, on the presumption of collective liability of lineage members for each other's conduct and debts ... He also actively supported the generation of well-endowed lineage estates ... for ... collective welfare purposes ... with the twin goals of ameliorating class conflict and reducing the size of government" (Rowe, 1998, pp. 382-3). In following such policies, Chen was following the examples of previous reformers such as $\mathrm{Gu}$ Yanwu (1613-82) who argued that increasing the lineage's judicial authority would reduce the judicial workload and hence the size of the bureaucracy (ibid, p. 383).

Important variations over time and places notwithstanding, the Chinese state relied on the administrative service of clans. ${ }^{33}$ Some of the clans' administrative duties were unofficial but emerged due to clans' members geographical concentration. Under the Ming, for example, local households were jointly liable for tax payment. The geographical concentration of clans rendered it the de-facto tax-bearing unit. The right to select local leaders as intermediaries in the relations with the state had a similar effect. ${ }^{34}$

In other administrative areas, such as adjudication, clans had a formal role. Clans were expected to resolve civil and commercial disputes among their members and among them and members of other clans. ${ }^{35}$ Ancestral halls served as a meeting place for clans' leaders who, among other roles, arbitrated disputes (Ruskola, 2000, p. 1631). In short, "a localized lineage was normally the largest unit within which disputes between its members were settled" (Freedman, 1966, p. 114).

The judicial roles of the clan explains the otherwise puzzling observation that China invested surprisingly little in legal infrastructure. China did not develop a judicial administrative branch and adjudication was provided by the magistrates among their many other roles even though they usually had no legal training. Moreover, the number of legal specialists in China during the 19th century was a tenth of the number of lawyers in England at

\footnotetext{
${ }^{33}$ E.g., Huang (1985), pp. 224-41; Heijdra (1998), pp.468-70.

${ }^{34}$ E.g., Deng (2004), p. 37.

${ }^{35}$ Clans were not 'imperia in imperio' and dissatisfied clan members could appeal, and did appeal, to the Imperial legal system (Ruskola, 2000, p. 1663).
} 
the time. ${ }^{36}$ Finally, China did not develop commercial legal code until the late 19th century and compromise was the underpinning principal of civil and commercial adjudication. ${ }^{37}$

Our analysis explains why the central authorities preferred to rely on this quasi-private enforcement despite the economies of scale in law enforcement. Limited morality reduced intra-clan enforcement cost and increased inter-clan enforcement cost. Thus the state had less to gain from creating an effective and impartial commercial and civil legal system. As noted by a prominent scholar of China, "because of the feeling of mutual responsibilities and because of its [the clan's] ability to maintain high moral standard among its members ... the state has found it convenient to leave to it considerable judicial powers" (Hu, 1948, p. 10). Moreover, an effective and impartial legal system would have undermined the clans, an outcome contradictory to the interests of the elders who controlled the clans and the state that used them. Clan rules regularly discouraged litigation and favored arbitration provided by the clan (Liu, 1959), while the state rewarded clans whose members did not use the court for a period of time.

In Europe, similar complementarities between the state and corporations were exploited by rulers. Pre-modern European states extensively relied on administrative capacity provided by corporations. Among other functions, cities and other corporations collected tax, provided navies, mustered armies, and administered justice. Consider, for example, the provision of poor assistance. Prior to the Reformation it was the responsibility of the Church, a corporation. In Protestant states, after the Reformation, it was provided by other corporations such as the English parishes and Friendly societies.

As is well known, the European self-governed cities were particularly important in providing administrative services. For much of the pre-modern period, European cities had some degree of independent administrative, financial, judicial, and military capacities. These capacities were harnessed by states for the provision of public and club goods such as protection, contract enforcement, and social safety nets (e.g., Pirenne, 1969; Tilly, 1989). Even after the rise of central administration, self-governed cities remained an important component of the administrative apparatus of even strong states such as France or Germany after its unification in 1871.

The following examples illustrate the role of cities in providing administrative services. In England, the confederation of the Cinque Ports in Kent and Sussex was the official provider of naval force to the Crown from 1155 to the 16th century. Around 1834, several hundreds self-governing corporations provided civil adjudication for about 16 percent of the English population. ${ }^{38}$ In Germany, various leagues of the Swabian cities (1331 to 1534) were responsible for law and order having, for a period, a standing army of 10,000 men. These leagues fought renegade dukes and played a decisive role in foreign wars.

The role of bailiffs and runners in the administration of the state. The distinct cultural and social foundations of cooperation in China and Europe also influenced the nature and capacities of state administrations. In China the state could not rely on the local social

\footnotetext{
${ }^{36} \mathrm{Li}$ Chen (2012), p. 2 and Fisher (1852), vol. 2, p. 153.

${ }^{37}$ The state enforced, however, legal rights over taxable land. For illuminating discussions of the legal system and the scholarly debate about its nature see also Nakamura (2004) and Ma (2007).

${ }^{38}$ Ajudication: Commission for Inquiring into the State of the Several Municipal Corporations. Great Britain (1839). Pp. 375, 678.
} 
organizations to implement policies contrary to their interests. Moreover, strengthening and institutionalizing lineage power increased the ability of clans to resist state authority (Rowe, 1998, Hung, 2009). As a result, the Chinese state authorities delegated to the clan the implementation of mutually beneficial policies, but relied on a parallel administration to implement policies which the clans did not favor. Such policies were physically implemented by a paid local staff, typically the "runners" (yamen). The runners were so important that a late Imperial magistrate noted that they "were an official's claws and teeth, and their services could not be dispensed with for a single day or in a single task" (Ch'ü, 1970, p. 57). Among other tasks the runners collected tax and debt, acted as a police force, arrested criminals and imposed punishments. In terms of the tasks they performed, the runner was the equivalent of the bailiff in England or the vogt in German speaking countries.

Although the tasks of the runners and the European bailiffs (we use this term generically) were similar, our conjecture implies that the runners and the bailiffs would have very distinct roles in supporting cooperation. If generalized morality prevailed in Europe, many of the bailiffs' tasks were in accordance to the prevailing morality. A bailiff who pursued a delinquent debtor or collected the poor rate from land owners was the means through which cooperation was achieved. This, if our analysis is correct, should have not been the case in China, in which the runners were the means to enforce the will of the state when it was not in a clan's interest to cooperate.

The implication is that in China runners should have been looked down upon as immoral even by the magistrates who employed them. The runners were locals - a necessary condition for the lowest level administration to be effective at the time - who nevertheless were willing to take actions that harmed other locals, potentially even their kin. They were willing to put obedience to law above their moral obligations. In short, if our analysis is correct, one who became a runner in China had revealed himself immoral by the prevailing standard, while a European bailiff did not. If so, the Chinese runners were more likely to be individuals with low social rank who could not be trusted even by the authorities which they served.

In fact, most of the runners were poor, some had a criminal recods, and most had no propety (Ch'ü, 1970, p. 63). The evidence regarding the legal designation of the runners confirms that the authorities held the runners who served them in contempt. Runners were "legally classified as "mean" people ..., a status comparable to that of a prostitute, actor or slave. Like all other "mean" people, they were discriminated against. They were not allowed to take civil service examinations and were prevented from entering officialdom. The law stipulated that any of them who took the civil service examinations or purchased an official title was to be dismissed and given 100 strokes. The offspring were similarly deprived" (ibid, p. 62). ${ }^{39}$ The distinction from Europe is striking, In England, for example, only a freeman could have been a bailiff, while in China a runner's legal definition was equivalent to that of a slave. The adverse selection of runners and the institutionalized and cultural discrimination against them implied that runners would be corrupt unless deterred by the expected response of the magistrate. The historical relevance of this possibility is clear from the length to which the magistrates tried to prevent this outcome. To illustrate, the collection of tax by the runners was done for a period of time by the taxpayers handily placing the tax

\footnotetext{
${ }^{39}$ Runners had a term limit although in many cases they captured their positions and gained de-facto rights over them. See Ch'ü (1970), pp. 63-4 and Reed (2000).
} 
in locked boxes that the runners took to the magistrate who had the key to open these boxes. Yet runners often abused the posts. An inquiry of tax shortfall in the Jiangsu province in 1788 revealed that $41 \%$ was the result of corruption by the runners (Kiser and Tong, 1992, p. 318$) \cdot{ }^{40}$

Summarizing, state and market institutions adapted to the underlying cultural and social foundations that sustained local cooperation in China and Europe. This further reinforced the underlying social structures and accentuated the institutional and cultural divergence between China and Europe. ${ }^{41}$

\section{$5 \quad$ Persistence of Kinship Ties in Modern China}

Overtime the attitude of the Chinese state towards clans changed particularly due to the realization of the higher institutional effectivness in the West. Rather than relying clans for local public good provision, the state began to seek alternatives. Hostility towards clans was explicit during the modernization movement in the early 20th century, when clans were viewed as an obstacle to economic development. But things got much worse when the communist regime gained power in 1949: clans were officially abolished, their properties were confiscated, elders lost their legal privileges and authority, clan legal codes were no longer recognized, and the ideology of class consciousness was promoted (e.g., Huang, 1985, p. 308). ${ }^{42}$ Had the clans been a product of the state, they would not have survived the crackdown. This is not what happened, however. When the state stopped actively persecuting them in 1979, clans re-emerged, consistently with the idea that clans coevolved with deeply held moral convictions. We now document the re-emergence of clans and the persistence of cultural traits in modern China.

\subsection{The re-emergence of clans in China}

A first indicator of the re-emergence of clans in post Maoist China is the pattern of publication of genealogies. Our genealogy data set, discussed above, provides the date of publication for about $86 \%$ of the genealogies and, as can be expected, only a few genealogies were written under communism. Between 1949 (when the Republican forces were defeated) to 1979 (when the market reforms began) only 298 genealogies were published. More informative is that $179(60 \%)$ of them were published in Taiwan to which the republican forces retreated. In fact, more genealogies were published in Taiwan between 1949 and 1979 than we have records for since the Ming came to power in 1368. The Chinese version of Republicanism was more clannish than the European one in which it is associated with individualism.

\footnotetext{
${ }^{40}$ Specifically, the corruption was by the runners and clerks (who were also low level local assistants of the magistrates). Local tax evasion by wealthy and powerful landowners accounted for about $55 \%$ of the total.

${ }^{41}$ Our analysis similarly provides a consistent explanation to other institutional distinctions such as the prevalence of the gentry, the household registration system, and the civil examinations system in China but not in Europe. For some recent works on these issues, see Huen (1996), Chen (2012), Ma (2007), Zelin et al. (2004), Huang (2001) and Bourgon (2002).

${ }^{42}$ Yet some policies under communism actually strengthened limited morality. Among these policies were legal restrictions on geographical mobility, collectivization, and the delineation of village boundaries (e.g., Huang, 1985).
} 
In mainland China, the publication of genealogies resumed after 1979 (figure 6). Our sample contains 4,650 genealogies that were published from 1644 to 2005 of which 1108 (23.7\%) were published from 1979 to 2005, about 42 genealogies per-year. The selection bias favoring post-1979 genealogies notwithstanding, this is more genealogies per-year than during the Qing dynasty (7) and the Republican period (35.6). Also telling is that even after the collapse of the Empire in 1911, genealogies continued to be published. Whatever role the Empire played in the diffusion of clans, by 1911 the perpetuation of the clans did not rely on this role.

$<<$ Insert figure 6 around here $>>$

Figure 6: Genealogies by Period and Region, 1644-2005

\begin{tabular}{lccccccc} 
Period written & No. & $\%$ & East & North & South & West & Cities \\
\hline 1644_1911 & 1,890 & $41 \%$ & 1134 & 68 & 498 & 92 & 31 \\
1911_1949 & 1,354 & $29 \%$ & 723 & 24 & 444 & 96 & 24 \\
1949_1979 & 298 & $6 \%$ & 36 & 4 & 12 & 19 & 2 \\
Post_1979 & 1,108 & $24 \%$ & 360 & 29 & 313 & 170 & 14 \\
Total & 4,650 & $100 \%$ & 2253 & 125 & 1267 & 377 & 71
\end{tabular}

Source: Our sample from Wang (2008).

The post-1979 re-emergence of clans is particularly noteworthy given that the reforms were not designed to foster clan organizations. Households, and not clans, were given landuse rights in the former collective farms and privately-owned businesses were permitted. Yet, kin-based and relations-based exclusive organizations have re-emerged and resumed their traditional role in supporting cooperation.

One may wonder if the publications of the genealogies reveals no more than the common curiosity about family history. This is not the case, however. Clans still matter. To illustrate, a county-level survey in 2000 (by Liangqun and Murphy, 2006, in Jiangxi) documents that 70 surnames out of 99 (in 40 villages) updated their genealogies since 1981 and 41 surnames invested in their ancestral shrines since 1991 (p. 230). A 2002 representative national survey of more than 300 villages reveals lineage activities and kinship organizations in 66 percent of the villages (Tsai, 2007, pp. 154-7). Clans resumed their role in securing property rights from predation by officials, organizing weddings and funerals, providing welfare, contributing to public projects, and promoting mutual aid arrangements (ibid). Inter-clan conflicts also resumed and collectively owned rural firms often formally exclude non-locals (Thøgersen, 2002). About 90 percent of the 887 households that migrated to or from one of 50 villages relocated to their 'ancestral village' and 60 percent relocated due to inter-lineage tension (Liangqun and Murphy, 2006, p. 623).

As a second indicator of clan persistence, we study a random sample of 76 counties, 205 villages and 4274 individuals from China General Social Survey, 2005 (GSS05). The GSS05 asks (only) rural residents whether there is a clan organization in their community. Although 
under-reporting of clan organizations is likely given the tradition of suppression by the communist authorities, the census reveals 277 clan-based organizations. A clan organization almost always (90 percent) has a genealogy, a graveyard, or both. On average there is 1.35 clan organization per-village and one organization per 15.5 respondents. Almost 70 percent of the population live in a county with positive sample probability of a village having an organization, and in 41 percent of the counties the village-probability of having a clan organization is at least 50 percent. The survey also asks whether the clan is a surname-based or temple-based organization. ${ }^{43}$ The two types differ in their assets such as land, estates (other than ancestral hall), and trust funds. Only 26 percent of the surname-based network have such an asset, compared to 78 percent of the temple-based organizations. Clan organizations currently exist in each of China's six regions although there are no temple-based clan organizations in the north (figure 7). Contemporary clans (and temple based clans) are particularly frequent in the south-central region and, specifically, in Guangdong, the richest province. This geographic pattern is consistent with the history of the rise of clans associated with out-migration from the North, as described in subsection 4.1.

$$
<<\text { Insert figure } 7 \text { around here }>>
$$

Figure 7: Clan Organizations in Rural China, 2006

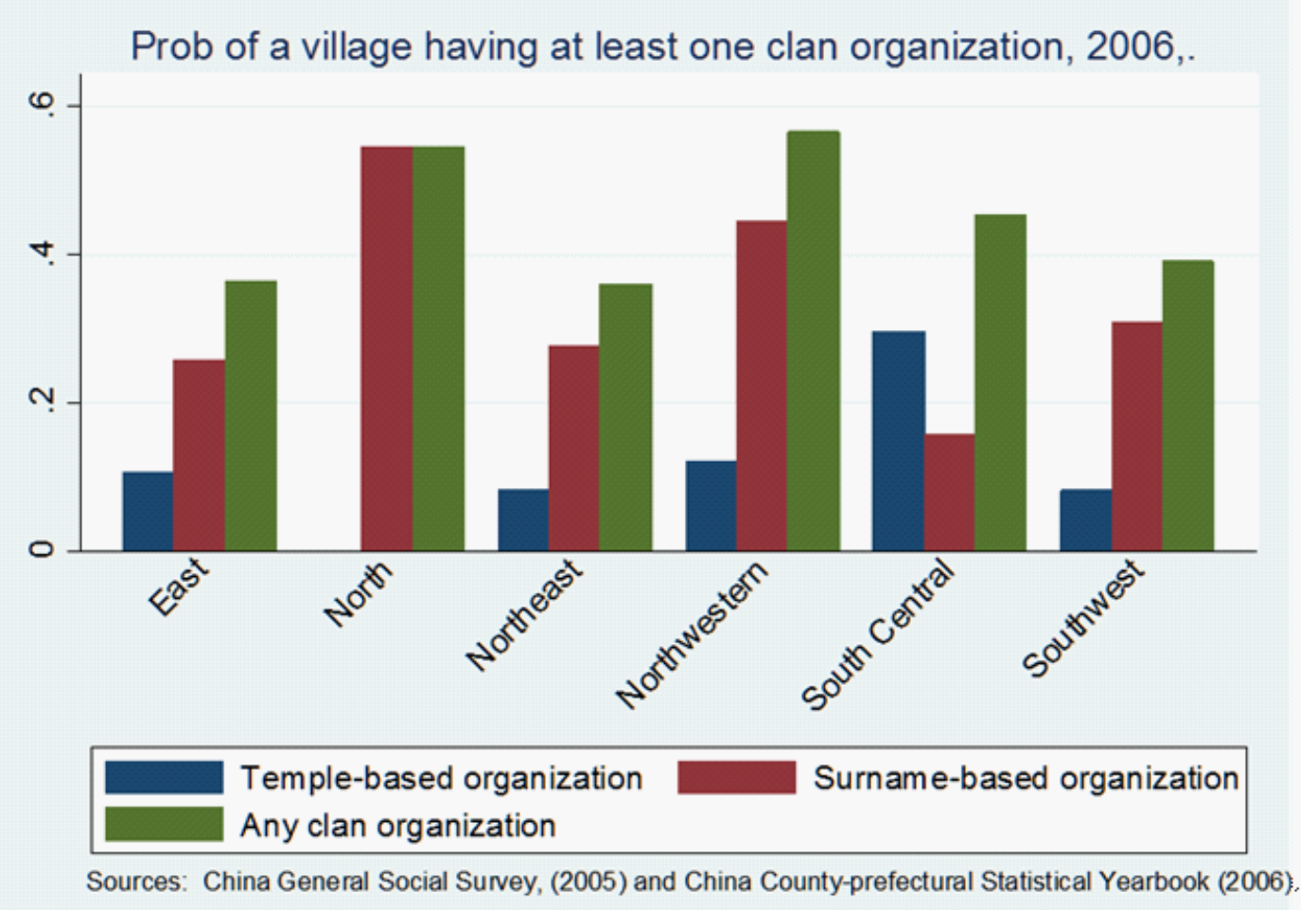

\footnotetext{
${ }^{43} \mathrm{~F} 10$. 'Is there any clan network or organization in your community/village? 1 None. 2 There are kinship network bounded by family name, but no formal organization. 3 There are clan organization centered around clan temple activities.'
} 
The majority of clans mentioned in the survey fulfill functions such as resolving private disputes within the village, providing local public goods and economic assistance, and handling inter-village relations. This is confirmed by other sources, that describe how clans secure property rights (also preventing abuse from local officials), organize weddings and funerals, provide welfare, contribute to public projects (e.g., road's construction), and promote mutual aid arrangements. For example, in River county (Jiangxi) descent groups re-grouped to protect land-user rights (Liangqun and Murphy, 2006, p. 632) and village-wide lineage groups are significantly correlated with the provision of public goods and with how public officials are held accountable (Tsai, 2007). There is also a strong and significant correlation of village-level kinship with the number of private enterprises and the labor force (Peng, 2004). ${ }^{44}$

Chinese scholars have noted the important role of kin and kin-like relations in the success of market reforms. China's formal institutions are well known to be weak and do not adequately secure private property rights or enforce contracts; clans filled this vacuum and partly fulfilled these functions, as they had done in the past. ${ }^{45}$ Prior to 2007 all property in China was de jure owned by the state and there was no law recognizing and regulating private property rights. ${ }^{46}$ There was no dedicated contract law prior to 1981 and only in 1999, a Uniform Contract Law had been formulated. As noted by Li (2009, p. 20), this law, which is still in force, is ineffective because it is ambiguous, ill specified, and lacks a proper case notes. Moreover, the legal system is subservient to the interest of the state. The inadequacy of China's formal institutions manifests itself in the widespread reliance on political actors (e.g., party cadres) in business enterprises (e.g., Nee, 1992) and the evidence suggests that 'buying' political protection in this manner is costly. ${ }^{47}$ This weakness of the state left room for the proliferation of social organizations based on relationships and affinity such as guanxi (relations; e.g., Thøgersen, 2002, p. 261) and clan-like organizations. ${ }^{48}$ Guanxi in turn reflects and reinforces limited morality, through the services it provides to individuals in their economic activity. To illustrate, job assignment in the 1980s was formally based on meritocracy. Yet, in a representative sample of 1,008 households in the city of Tianjin (1988), 57 percent reported that they got their jobs (1977-1988) based on personal connections (guanxi) and 43.3 percent of those who assisted them were relatives (Bian, 1994). In this way, the mutual reinforcement between kin based organizations and loyalty to kin is preserved in modern China.

\subsection{Cultural persistence}

The strength of kinship ties in contemporary China is reflected in trust attitudes. In China "you trust your family absolutely, your friends and acquaintances to the degree that mutual dependence has been established ... With everybody else you make no assumptions about

\footnotetext{
${ }^{44}$ Data from 366 villages in 22 counties. The effect is smaller including self-employed but significant; $7 \%$ increase per $10 \%$ increase in the proportion of the largest group.

${ }^{45}$ E.g., Nee (1992) and Whyte $(1995,1996)$.

${ }^{46}$ E.g., Zhang (2008); Yet, article 11 of the 1988 constitutional amendment permitted private enterprises.

${ }^{47}$ E.g., Bai et al. (2006), Lu and Tao (2010), Su and He (2010), Li et al. (2008), Lu, Tao and Yang (2010), Thøgersen (2002).

${ }^{48}$ Regarding fictional clans is Late Imperial China, see Rowe (2002), pp. 355-7.
} 
their good will" (Redding, 1993, p. 66). ${ }^{49}$ The 2005 China General Social Survey asked villagers how much they trust a villager with the same surname vs. a villager with another surname (qf14). An unconditional mean comparison test of the resulting 4228 responses in random sample of 76 counties reveals a statistically significant lower trust (at the 1 percent level) in villagers of different surname.

The World Value Surveys allow one to compare attitudes across countries. In the first time China was included (1990), 60 percent of the Chinese responded that most people can be trusted. ${ }^{50}$ This is much higher rate than in the West (i.e., France, GB, USA, and Germany) led by the USA with 51.2 percent. The response to a more specific question about trust, however, reveals the opposite. Only 11.6 percent of Chinese "trust completely" other "people in the country" compared to an average of 16 percent in the West. Moreover, the World Value Survey of 1990 is the only one to ask about trust toward individuals of different social distance. The respondents were asked to "say how much you trust the following groups of people." The level of trust in family was the highest in both China and the US. The levels of trust toward strangers, however, differed. In the US, these levels remained relatively high, about 50 percent, while in China they dropped to 10 percent (Buchana and Crosonb, 2004, pp. 489-490). Later surveys conducted in 2006 and 2007 asked about trusting a person whom one met for the first time. Only 11.3 percent of Chinese trust a person whom they met for the first time compared to between 26.1 percent to 49.3 percent in the West. While almost 90 percent of Chinese do not trust (much or at all) a person whom they met for the first time, only 60 percent feel the same in the West. Complete trust in people that one knows personally is 20.5 percent in China, but 31.6 percent in the West.

To overcome the difficulty of comparing attitudes across countries, where the same question can have different interpretations, we collected data on the attitudes of Chinese vs. European immigrants to Canada, exploiting the 2005 Ethnic Diversity Survey. We restrict attention to immigrants of second generation or higher. These are individuals born in Canada, and who report their ethnic ancestry.

We focus on trust towards different reference groups, exploiting a question that asks "How much do you trust each of the following groups: people in your family / people that you work with / people in your neighborhood?". The answer can vary from 1 (not at all) to 5 (a lot). We also compare trust attitudes in general, with the usual question on trust towards people in general ("Generally speaking would you say that most people can be trusted or that you cannot be too careful in dealing with people?", with a binary answer (1 if people can be trusted, 0 otherwise). Compared to European immigrants, we expect Chinese immigrants to display more trust in people who are closer (such as family members), and less trust in people who are more distant (such as in the general trust question). More generally, as familiarity or closeness decreases, we expect trust to decline more steeply for Chinese immigrants compared to European immigrants.

Figure 8 reports the estimates for the different trust attitudes. Estimation is by OLS for

\footnotetext{
${ }^{49}$ Chinese overseas businessmen perceive Westerners as more contractually reliable. A survey of Chinese businessmen in Thailand and Hong-Kong (1994-5) finds that "Westerners are considered [by the Chinese] to be attractive partners for ... their respect for the law and keeping of promises. Trustworthiness is a frequently mentioned trading attribute of non-Asians" (Pyatt and Redding, 2000, p. 59).

${ }^{50}$ World Values Survey, Roland Inglehart, et al. (1998) and the World Value Survey, 2005-8. See: www.worldvaluessurvey.org.
} 
trust in family members, colleagues and neighbors, and by Probit for general trusts (marginal effects are reported). Thus, the coefficient estimates are strictly comparable only for the first three measures of trust, and not for general trust. The dummy variable Chinese vs. European takes a value of 1 for Chinese ancestry, and 0 for ancestry in Northern and Central Europe. It is coded as missing for ancestry from other parts of the world. ${ }^{51}$ Throughout we also control for individual education, age, income, gender, and other observable individual features (see the Notes to figure 8 ). As shown in Panel A of figure 8, Chinese and European immigrants have similar levels of trust towards family members and colleagues at work (columns 1 and 2). When it comes to trust towards neighbors or people in general, however, Chinese immigrants are significantly less trusting than European immigrants (columns 3 and 4).

Could these results reflect the possibility that Chinese immigrants find it more difficult to fully integrate in a Western society, because of their different ethnic traits? To address this concern, Panel B of figure 8 adds a regressor that controls for whether the respondent ever felt uncomfortable up until the age of 15 because of his /her ethnic identity (the variable uneasy). With this specification, the results are unchanged or even stronger. Chinese immigrants have relatively more trust in family members compared to European immigrants. This difference remains positive but it loses significance with respect to colleagues, and it becomes negative and statistically significant when turning to neighbors and to general trust. Altogether, these results confirm that the different cultural traditions of China and the West continue to shape attitudes today.

\section{$<<$ Insert figure 8 here $>>$}

\section{Concluding Remarks}

Positive feedbacks amplified different initial conditions that prevailed in Europe and China over a millennium ago. In China, clans became the locus of cooperation among kin motivated by reciprocal moral obligations and personal interactions. In Europe, corporations became the locus of cooperation among non-kin motivated by generalized morality and legal enforcment. These social organizations influenced the institutional foundations of markets, the provision of social safety nets, legal development, and the organization of the state. These effects persist today.

Persistence, however, does not mean stasis and both systems were successful in adapting to change. Yet their dynamics differed due to the complementarity between their different constituent elements. ${ }^{52}$ For example, the Europeans responded to the technologically driven increase in economies of scale by relying on the law and generalized morality to separate ownership and control of corporations. In China, kinship organizations were supplemented by "more flexible, selective, and contingent networks that include other kin and relatives" (Thøgersen, 2002, pp. 267). Thus, the European system has a comparative advantage in

\footnotetext{
${ }^{51}$ Thus, immigrants from Southern Europe (Italy, Spain, Greece, and Portugal) are excluded from the comparison, because trust is traditionally low in this part of Europe- indeed the term amoral familism was introduced by Banfield (1967) precisely in his analysis of Southern Italy.

${ }^{52}$ See the discussion in Greif (2006) on institutional dynamics as a historical process.
} 
Figure 8: Trust attitudes: Chinese vs European immigrants

\begin{tabular}{lcccc}
\hline $\begin{array}{l}\text { Dependent Variable } \\
\text { Estimation technique }\end{array}$ & $\begin{array}{c}(1) \\
\text { Trust family } \\
\text { OLS }\end{array}$ & $\begin{array}{c}\text { Trust colleagues } \\
\text { OLS }\end{array}$ & $\begin{array}{c}(3) \\
\text { Trust neighbors } \\
\text { OLS }\end{array}$ & $\begin{array}{c}(4) \\
\text { General Trust } \\
\text { Probit }\end{array}$ \\
\hline & & PANEL A & & \\
Chinese vs European & -0.002 & -0.055 & $-0.220^{* * *}$ & $-0.060^{* * * *}$ \\
& $(0.022)$ & $(0.038)$ & $(0.039)$ & $(0.021)$ \\
Observations & 17,352 & 14,677 & 17,278 & 17,207 \\
R2 & 0.015 & 0.049 & 0.102 & 0.026 \\
& & & & \\
Chinese vs European & $0.055^{* *}$ & 0.050 & $-0.125^{* * *}$ & $-0.045^{* *}$ \\
& $(0.023)$ & $(0.039)$ & $(0.039)$ & $(0.021)$ \\
Uneasy & & & & $-0.019 * * *$ \\
& $-0.073^{* * *}$ & $-0.137 * * *$ & $-0.122^{* * *}$ & $(0.006)$ \\
Observations & $(0.008)$ & $(0.012)$ & $(0.011)$ & 17,182 \\
R2 & 17,325 & 14,662 & 17,252 & 0.027 \\
\hline
\end{tabular}

Robust standard errors in parenthesis: * significant at 10\%; ** significant at 5\%; *** significant at $1 \%$

Column (4) reports marginal effects and Pseudo R-squared.

supporting impersonal exchange, while the Chinese system has a comparative advantage in economic activities in which personal relations are more important. Their relative efficiency is apriori unclear, as each system has advantages and drawbacks. ${ }^{53}$

We have only scratched the surface of a rich research program, and many questions remain to be addressed. Three issues in particular are highlighted by the preceding analysis and deserve more attention. First is the question of how theses different social and cultural heritages influenced specific economic and political outcomes and the pattern of economic development in Europe and China. For instance, Europe's transition to a modern economy and its successful post World War II reconstruction benefited from its social welfare systems routed in generalized morality and legal institutions. However, the subsequent dynamic of the welfare state led to entitlement programs that, in some European states, are fiscally unsustainable. In contrast, post-reform China experienced rapid economic growth, despite weak legal institutions, because its traditions foster individual profit-seeking on the one hand, and relations-based institutions for enforcement and public good provision on the other. Yet, limited morality and institutions based on personal relations also lead to potentially destructive inequality, corruption, and social tensions. We plan to explore these issues in a follow-up project.

Second is the issue of state formation. We have stressed how the modern state was built incorporating and exploiting elements of the underlying social organizations. Exploring

\footnotetext{
${ }^{53}$ For a similar observation regarding Europe and the Middle East, see Greif (1994, 2006).
} 
more in detail how this happened, at critical historical junctures and with regard to specific institutions, can shed light on the functioning of state institutions, on their cultural and social prerequisites, and on why institutional transfer can fail if these historical prerequisites are missing.

The third general issue concerns the importance of endogenous social organization and their formation in situations of social conflict. Most of political economics takes the social groups as primitive entities, defined by common economic interests, and then studies which groups are politically more influential in lobbying, or at the elections, or in shaping the evolution of political institutions. This is unsatisfactory, because it neglects the collective action problem faced by any group. In our analysis, social organizations are endogenous, and group formation reflects both external incentives and group loyalty. We have refrained from studying situations of social conflict, however, where different groups compete for influence or power. Extending our approach to study social conflict can provide fruitful insights about how social groups shape political outcomes and political institutions.

\section{References}

Acemoglu, Daron and James Robinson. 2012. Why Nations Fail: The Origins of Power, Prosperity, and Poverty. Crown Business.

Ahern, Emily. 1976. "Segmentation in Chinese lineages: a view from written genealogies." American Ethnologist, 3: 1-16.

Analects of Confucius: A Philosophical Translation. 1999. Translated by Roger T. Ames and Henry Rosemont Jr. Ballantine Books. Random House.

Ashley, William James 1909 [1888]. An Introduction to English Economic History and Theory. Part 1. The Middle Ages. 4th ed., Online, McMaster University. http://econpapers.repec.org/bc

Bai, C.E., J. Lu, and Z. Tao. 2006. "Property Rights Protection and Access to Bank Loans: Evidence from Private Enterprises in China." Economics of Transition 14 (4): 611-628.

Greif, Avner. 1994. "Cultural Beliefs and the Organization of Society: A Historical and Theoretical Reflection on Collectivist and Individualist Societies." The Journal of Political Economy, vol. 102, No. 5 (October): 912-50.

Ballard, Adolphus. 1913. British Borough Charters 1042-1216. 2010 ed., Cambridge: Cambridge University Press.

Ballard, Adolphus, and James Tait (eds.). 1923. British Borough Charters, 1216-130\%. Cambridge: Cambridge University Press.

Banfield, E.C. 1967. The Moral basis of a Backward Society. New York: Free Press. 
Barber, Malcolm. 1995. The New Knighthood: A History of the Order of the Temple. Cambridge: Cambridge University Press.

Ben-Amos, I.K. 2000. "Gifts and Favors: Informal Support in Early Modern England." The Journal of Modern History, 72(2): 295-338.

Beresford, M. and H. P. R. Finberg. 1973. English Medieval Boroughs: A Handlist. Newton Abbott: David and Charles.

Berman, Harold J. 1983. Law and Revolution: The Formation of the Western Legal Tradition. Cambridge, MA: Harvard University Press.

Bian, Y. 1994. "Guanxi and the Allocation of Urban Jobs in China." The China Quarterly, 140: 971-999.

Boerner, L. and D. Quint. 2010. "Medieval Matching Markets." Memo. Free University Berlin.

Bourgon, Jerome. 2002. "Uncivil Dialogue: Law and Custom Did not merge into Civil Law under the Qing." Late Imperial China, 23(1): 50-90.

Brandt, L., D. Ma, and T.G. Rawski. various versions, 2011-13. "From Divergence to Convergence: Re-evaluating the History Behind China's Economic Boom." Working Paper. University of Toronto.

Brenner, Robert. 1987. "Agrarian Class Structure and Economic Development in Pre Industrial Europe." In T.H. Aston and C.H.E. Philpin (eds), The Brenner Debate. Agrarian Class Structure and Economic Development in Pre Industrial Europe. Cambridge: Cambridge University Press. 10-63.

Brenner, R. and C. Isett. 2002. "England's Divergence from China's Yangzi Delta: Property Relations, Microeconomics, and Patterns of Development." The Journal of Asian Studies, 61(2): 609-662.

Buchana, N. and R. Crosonb. 2004. "The boundaries of trust: own and others' actions in the US and China." Journal of Economic Behavior \& Organization, 55: 485-504.

Cantoni, Davide and Noam Yuchtman. 2014. "Medieval Universities, Legal Institutions, and the Commercial Revolution." Quarterly Journal of Economics, 129(2): 823-887.

Chen, Li. 2012. "Legal Specialists and Judicial Administration in Late Imperial China, 1651-1911." Late Imperial China, 33(1): 1-54.

China General Social Survey, 2005. Survey Research Center, HKUST.Survey Research Center, HKUST \& Sociology Department of Renmin University. http://www.src.ust.hk/survey/GSS (Jan. 2015).

The China County-prefectural Statistical Yearbook, 2006. 
Ch'u, Tung-tsu. 1970. Local Government in China Under the Ch'ing. Cambridge, MA: Harvard University Press.

Clark, D. S. 1987. "The Medieval Origins of Modern Legal Education: Between Church and State." The American Journal of Comparative Law, 35(4): 653-719.

Cohen, Myron. 1990. "Lineage Organization in North China." The Journal of Asian Studies, 49(3): 509-534.

Commission for Inquiring into the State of the Several Municipal Corporations in England and Wales. 1839. Analytical index to the reports of the Commissioners appointed to inquire into the municipal corporations (England and Wales): ordered, by the House of Commons, to be printed, 15 July 1839. Great Britain. London: s.n..

Davis, John. P. 1961. Corporations: A Study of the Origin and Development of Great Business Combinations and of their Relation to the Authority of the State. New York: Capricorn Books.

Dawson, Miles Menander (ed.). 1915. The Ethics of Confucius. New York: Putnam.

de Moor, T., 2008. "The Silent Revolution: A new perspective on the emergence of commons, guilds, and other forms of corporate collective action in Western Europe." The International Review of Social History (special issue on guilds), 53 (suppl. 16): 175208.

de Roover, Florence Edler. 1945. "Early Examples of Marine Insurance." Journal of Economic History, 5: 72-200.

Deng, Kent. G. 2000. "A Critical Survey of Recent Research in Chinese Economic History." Economic History Review, LIII: 1-28.

Deng, Kent. G. 2004. "Unveiling China's True Population Statistics for the Pre-Modern Era with Official Census Data." Population Review, 43(20): 32-69.

Dollinger, Philippe. 1970. The German Hansa. Stanford: Stanford University Press.

Drew, K. Fischer. 1991. The Laws of the Salian Franks. Philadelphia: University of Pennsylvania Press.

Ebrey, Patricia Buckley and James L. Watson. 1986. Kinship Organization in Late Imperial China 1000-1940. Berkeley: University of California Press.

Ekelund, Robert B., Robert D. Tollison, Gary M. Anderson, Robert F. Hebert, and Audrey B. Davidson. 1996. Sacred Trust: The Medieval Church as an Economic Firm. Oxford: Oxford University Press.

English Historical Documents. 1968. Douglas, D. C. and Greenaway G. W. (eds). Vol. II: 1042-1189. London: Eyre and Spottiswoode. 
Faure, David. 2007. Emperor and Ancestor: State and Lineage in South China. Stanford: Stanford University Press.

Fisher, Richard Swainson, 1852. The Book of the World, Volume 2, New York: Colton.

Folena, G. 1970-1. "Gli Antichi Nomi di Persona e la Storia Civile di Venezia", in Atti dell'Istituto Veneto di Scienze, Lettere ed Art, Venezia.

Freedman, M. 1966. Chinese Lineage and Society: Fukien and Kwangtung. London: Athlone.

Friedmann, J. 2007. "Reflections on Place and Place-making in the Cities of China." International Journal of Urban and Regional Research, 31(2): 257-279

Gellhorn, W. 1987. "China's Quest for Legal Modernity." Journal of Chinese Law, 1(1): $1-22$.

Gelderblom, O. 2013. "Cities of Commerce." The Institutional Foundations of International Trade in the Low Countries, 1250-1650. Princeton: Princeton University Press.

Goody, J. 1983. The Development of the Family and Marriage in Europe. Cambridge: Cambridge University Press.

Greif, A. 2005. "Commitment, Coercion, and Markets." in C. Menard and MM. Shirley (eds), Handbook for New Institutional Economics. New York: Springer.

Greif, A. 2006. Institutions and the Path to the Modern Economy. Cambridge, UK: Cambridge University Press.

Greif, A. 2006a. "Family Structure, Institutions, and Growth." American Economic Review. 96(2): 308-312.

Greif, Avner. 2006b. "The Birth of Impersonal Exchange: The Community Responsibility System and Impartial Justice." Journal of Economic Perspective, 20(2): 221-236.

Greif, Avner. 2008. "Toward Political Economy of Implementation: The Impact of Administrative Power on Institutional and Economic Developments". Elhanan Helpman (ed.), Institutions and Growth. Cambridge: Harvard University Press. 17-63.

Greif, Avner and Murat Iygun. 2013. "Social Organizations, Violence, and Modern Growth." American Economic Review (Papers 6 Proceedings), 103(3): 534-538.

Guichard, Pierre and Cuvillier, Jean-Pierre. 1996. "Barbarian Europe" in ed. Andr, Burguire et al A History of the Family, Vol. I, Cambridge: Polity Press. 318-378.

Guinnane T.W., Ron Harris, Naomi Lamoreaux, and Jean-Laurent Rosenthal. 2007. "Putting the Corporation in its Place." Enterprise and Society, 8(3): 687-729.

Heijdra, M. 1998 [2007], "The Socio-economic Development of Rural China During the Ming." in D. Twitchett and J. K. Fairbank (eds) The Cambridge History of China, vol. 8(2). Cambridge: Cambridge University Press. Ch. 9, 417-581. 
Herlihy, David. 1985. Medieval Households. Cambridge: Harvard University Press.

Hu, Hsien-Chin. 1948. The Common Descent Group in China and its Functions, New York: Viking Fund, Viking Fund publications in anthropology, no. 10.

Huang, P.C. 1985. The Peasant Economy and Social Change in North China. Stanford: Stanford University Press.

Huang, Philip C. 2001. Code, Custom, and Legal Practice in China, Stanford: Stanford University Press.

Huen, Wai-po. 1996. "Hukou System Household Registration System in the Qing Dynasty: Precursor to the PRC's." China Report, 32: 395-418.

Hughes, Diane Owen. 1974. "Toward Historical Ethnography: Notarial Records and Family History in The Middle Ages." Historical Methods Newsletter, 7(2): 61-71.

Hung, Ho Fung. 2009. "Cultural Strategies and the Political Economy of Protest in Mid. Qing China, 1740-1839." Social Science History, 33(1): 75-115.

Inglehart, R., M. Basanez, and A. Moreno. 1998. Human Values and Beliefs. A CrossCultural Sourcebook. Ann Harbor: Michigan University Press.

Jha, Saumitra. 2010. "Financial Innovations and Political Development: Evidence from Revolutionary England." Working paper. Stanford University.

Jútte,, Robert. 1996. "Poverty and Poor Relief." In Sheilagh Ogilvie (ed.). Germany. A New Social and Economic History, 1630-1880. Vol. II. London: Arnold.

Kelly, J.M. 2003 [1992]. A Short History of the Western Legal Theory. Oxford: Clarendon Press.

Kessler, A. 2007. A Revolution in Commerce, The Parisian Merchant Court and the Rise of Commercial Society in Eighteenth-century France. New Haven/London: Yale University Press

Kiser, Edgar and Xiaoxi Tong. 1992. "Determinants of the Amount and Type of Corruption in State Fiscal Bureaucracies: An Analysis of Late Imperial China." Comparative Political Studies, 25(3): 300-333.

Kulp, D. Harrison. 1925. Country life in South China: the sociology of familism. New York city: Bureau of publications, Teachers college, Columbia University. Vol. 1.

Kuhn, D. 2009. The Age of Confucian Rule: The Song Transformation of China. Cambridge: Harvard University Press.

Kuran, Timur. 2005. "The Absence of the Corporation in Islamic Law: Origins and Persistence." American Journal of Comparative Law, 53: 785-834. 
Kuroda, Akinobu. 2013. "Anonymous currencies or named debts? Comparison of currencies, local credits and units of account between China, Japan and England in the pre-industrial era." Socio-Economic Review, 11: 57-80.

Landa, J. T. 1981. "A theory of the, ethnically homogeneous middleman group: an institutional alternative to contract law." The Journal of Legal Studies, 10: 348-362.

Laslett, Peter. 1969. "Size and Structure of the Household in England over Three Centuries." Population Studies, 23(2): 199-223.

Li, G. 2009. "The PRC Contract Law and Its Unique Notion of Subrogation." Journal of International Commercial Law and Technology, 4(1): 12-21.

Li, H., L. Meng, Q. Wang, L.A. Zhou. 2008. "Political Connections, Financing and Firm Performance: Evidence from Chinese Private Firms." Journal of Development Economics, 87(2): 283-299.

Liangqun, L. and R. Murphy. 2006. "Lineage Networks, Land Conflicts and Rural Migration in Late Socialist China." Journal of Peasant Studies, 33(4): 612-645.

Liu, Hui-Chen Wang. 1959. "The Traditional Chinese Clan Rules." Monographs of the Association for Asian Studies, 7.

Liu, Kwang-Ching. 1988. "Chinese Merchant Guilds: An Historical Inquiry." The Pacific Historical Review, 57(1): 1-23.

Liu, William G (Guanglin). 2005. Wrestling for Power: the State and Economy in Late Imperial China (1000-1770). PhD Dissertation, Harvard University.

Lowndes, W and J. Debrett, 1789. Introduction to the Statistical Tables of the Principal Empires, Kingdoms and States in Europe. London: Stationers Hall.

Lu, J. and Z. Tao. 2010. "Determinants of Entrepreneurial Activities in China." Journal of Business Venturing, 25(3): 261 -273.

Lu, J., Z .Tao, and Z. Yang. 2010. "The Costs and Benefits of Government Control: Evidence from China's Collectively-owned Enterprises." China Economic Review, 21(2): $282-292$.

Ma, Debin. 2004. "Growth, Institutions and Knowledge: a Review and Reflection on 18th20th Century Chinese Historiography." Australian Economic History Review, 44(3): 259-77.

Ma, Debin. 2007. "Law and Economic Growth: the Case of Traditional China- a Review with Some Preliminary Hypotheses." Working Paper. London School of Economics.

Maddison, Angus. 2001. The World Economy: A Millennial Perspective. Paris: OECD.

Maine, Henry. 1999 [1861]. Ancient Law in Connection with the Early History of Society, and Its Relation to Modern Ideas. Kitchener: Batoche Books. 
Mann, Susan Jones and Philip A. Kuhn. 2008 [1978]. "Dynastic Decline and the Roots of Rebellion." In Fairbank, John K (ed). The Cambridge History of China. Volume 10: Late Ch'ing 1800-1911, Part I. On line ISBN 9781139054775. CUP

McCulloch, John Ramsay. 1851. A dictionary, geographical, statistical, and historical, of the various countries, places, and principal natural objects in the world. Illustrated with maps. 2 vols. London: Longman, Brown, Green and Longmans.

Mitterauer, Michael, and Reinhard Sieder. 1982. The European Family. Oxford: Basil Blackwell.

Mocarelli, L. 2008. "Guilds Reappraised: Italy in the Early Modern Period." International Review of Social History, 53: 159-178.

Moll-Murata, C. 2008. "Chinese Guilds from the Seventeenth to the Twentieth Centuries: An Overview." International Review of Social History, 53: 213-247.

Nader, Helen. 1990. Liberty in Absolutist Spain. The Habsburg Sale of Towns, 1516-1700. Baltimore and London: The Johns Hopkins University Press.

Nakamura, S. 2004. "Was Traditional Chinese Law a Mere Model? Part Two." International Journal of Asian Studies, 1(2): 297-322.

Nee, V. 1992. "Organizational Dynamics of Market Transition: Hybrid Forms, Property Rights, and Mixed Economy in China." Administrative Science Quarterly, 37(1): 1-27.

Nicholas, David. 1992. Medieval Flanders. New York: Longman Publishing Group.

North, D. C., J. J. Wallis, and B R. Weingast. 2009. Violence and Social Orders: A Conceptual Framework for Interpreting Recorded Human History. Cambridge: Cambridge University Press

Nunn N. 2012. "Culture and the Historical Process." Economic History of Developing Regions. 27(S1): 108-126.

Pasternak, Burton. 1969. "The Role of the Frontier in Chinese Lineage Development," The Journal of Asian Studies, Vol. 28 (3), pp. 551-561.

Peng, Y. 2004. "Kinship Networks and Entrepreneurs in China's Transitional Economy." American Journal of Sociology, 109(5): 1045-1074.

Pirenne, H. 1969. Medieval Cities: Their Origins and the Revival of Trade. Princeton: Princeton University Press.

Pomeranz, K. 2000. The Great Divergence: China, Europe and the Making of the Modern World Economy. Princeton: Princeton University Press.

Postan, M. 1928. "Credit in Medieval Trade." The Economic History Review, 1(2): 234-61. 
Pyatt, T.R., Redding, S.G. 2000. "Trust and forbearance in ethnic Chinese business relationships in Hong Kong and Thailand." Journal of Asian Business, 16(1): 41-63.

Razi Z. 1993. "The Myth of the Immutable English Family." Past ES Present, 140(Aug): $3-44$

Richardson, Gary. 2004. "Guilds, Laws, and Markets for Manufactured Merchandise in Late-medieval England." Explorations in Economic History, 41(1): 1-25.

Redding, S. G. 1993. The Spirit of Capitalism. Berlin: Gruyter.

Reed, Bradly W. 2000. Talons and Teeth. County Clerk and Runners in the Qing Dynasty. Stanford: Stanford University Press.

Reynold's. 1869. Miscellany of Romance, General Literature, Science and Art. Feb. 20(42): 157.

Reynolds, Susan. 1984. Kingdoms and Communities in Western Europe, 900-1300. Oxford: Clarendon Press.

Rosenthal J.L. and R.B. Wong. 2011. Before and Beyond Divergence. The Politics of Economic Change in China and Europe. Cambridge: Harvard University Press.

Rozman, Gilbert. 1973. Urban networks in Ch'ing China and Tokugawa Japan. Princeton: Princeton University Press.

Rowe, W.T. 1998. "Ancestral rites and political authority in late imperial China - Chen Hongmou in Jiangxi." Modern China, 24(4): 378 -407.

Rowe, W.T. 2002. "Social Stability and Social Change." In D. Twitchett and J.K. Fairbank (eds), The Cambridge History of China, vol. 9. Cambridge: Cambridge University Press. Ch. 9, 473-562.

Ruskola, T. 2000. "Conceptualizing Corporations and Kinship: Comparative Law and Development Theory in a Chinese Perspective." Stanford Law Review, 52(6): 15991729.

Schofield, Phillipp R. 2003. Peasant and community in medieval England, 1200-1500. MacMillan. New York.

Sella, Pietro. 1904. The Statutes the Commune of Bugelle (Biella) and the Documents Which Have Been Added. Biella at the Press of G. Testa. Online (June 2013): http://wiretap.area.com/Gopher/Library/Classic/Latin/Malin/biella.

Shiue, Carol H. and Wolfgang Keller. 2007. "Markets in China and Europe on the Eve of the Industrial Revolution." American Economic Review, 97(4): 1189-1216.

Skinner, W.G. 2001 [1974]. Marketing and Social Structure in Rural China. Ann Arbor: The Association of Asian Studies. 
Smith, Joanna F. Handlin. 1987. "Benevolent Societies: The Reshaping of Charity During the Late Ming and Early Ch'ing." The Journal of Asian Studies, 46(2): 309-337.

Sng, Tuan-Hwee. 2011. Size and Dynastic Decline: The Principal-Agent Problem in Late Imperial China 1700-1850. Princeton: Princeton University.

Sommerville, C. John. 1993. The Secularization of Early Modern England: From Religious Culture to Religious Faith. New York: Oxford University Press.

Stubbs, W. (ed.), 1913. Selected Charters and Other Illustrations of English Institutional History from the Earliest Times to the Reign of Edward the First. 9th ed. Oxford: Clarendon.

Strum, Daniel. 2013. The Sugar Trade Brazil, Portugal, and the Netherlands, 1595-1630. Stanford: Stanford University Press.

Su, J. and J. He. 2010. "Does Giving Lead to Getting? Evidence from Chinese Private Enterprises." Journal of Business Ethics, 93(1): 73 -90.

Szonyi, Michael. 2002. Practicing Kinship. Lineage and Descent in Late Imperial China. Stanford: Stanford University Press.

Tabellini, G. 2008a "The Scope of Cooperation." Quarterly Journal of Economics, 123: 905-950.

Tabellini, G. 2008b "Institutions and Culture." Journal of the European Economic Association, 6: 255-294. doi: 10.1162/JEEA.2008.6.2-3.255

Tait, James. 1936. The Medieval English Borough. Studies on its Origins and Constitutional History. Manchester: Manchester University Press.

Telford, T.A. 1986. "Survey of Social Demographic Data in Chinese Genealogies." Late Imperial China, 7(2): 118-146.

Thøgersen, S. 2002. "Book Review: Village Economy and Culture in Contemporary China." Modern China, 28: 253-274

Tilly, Charles. 1989. "Cities and States in Europe, 1000-1800." Theory and Society (Special Issue on Cities and States in Europe, 1000-1800), 18(5): 563-584.

Trenerry, C.F., 1926. The Origin and the Early History of Insurance Including the Contract of Bottomry. London: P.S. King \& Son

Tsai, L.L., 2007. Accountability without Democracy. Cambridge: Cambridge University Press.

Van Doosselaere, Quentin. 2009. Commercial Agreements and Social Dynamics in Medieval Genoa. Cambridge: Cambridge University Press. 
Vicar-General Marriage License Index (1694 to 1826). London: http://www.ellipsis.cx/ liana/names/ english/engsurlondon1541.html.

Voigtländer, Nico and Hans-Joachim Voth, 2013. "The Three Horsemen of Riches: Plague, War, and Urbanization in Early Modern Europe," Review of Economic Studies, Oxford University Press, 80(2): 774-811.

Wang, H. 2008. Zhongguo jia pu zong mu. (The Comprehensive Catalogue of Chinese Genealogies Di 1 ban. Shanghai: Shanghai gu ji chu ban she.

Watson, James. 1982. "Chinese Kinship Reconsidered: Anthropological Perspectives on Historical Research," The China Quarterly, 92(Dec): 589-622.

Weber, Max. 1968 [1915]. The Religion of China. Free Press; New edition.

World Value Survey. http://www.worldvaluessurvey.org/wvs.jsp

Whyte, M.K. 1995. "The Social Roots of China's Economic Development." China Quarterly, 144: 999-1019.

Whyte, M.K. 1996. "The Chinese Family and Economic Development: Development: Obstacle or Engine?" Economic Development and Cultural Change, 45(1): 1-30.

Wood, R. 2003. "Urbanization of Europe and China during the second millennium." International Journal of Population Geography, 9: 215-227.

Zelin, M., J. Ocko and R. Gardella (eds.). 2004. Contract and Property in Early Modern China, Stanford: Stanford University Press.

Zhang, M. 2008. "From Public to Private: The Newly Enacted Chinese Property Law and the Protection of Property Rights in China." Berkeley Business Law Journal, 5(2): 317-363.

Zhenman, Zheng. 1992. Family Lineage Organization and Social Change in Ming and Qing Fujian. 2001 English translation by Michael Szonyi. Honolulu: University of Hawaii Press. 


\section{Online Appendix}

\subsubsection{Proof of Lemma 1}

Exploiting the results and the notation in the text, we have:

$$
\begin{aligned}
& W^{\lambda n}\left(x^{\lambda n}, x^{\gamma n}\right)=1+\lambda-\tau+H\left(g^{n}\right) \\
& W^{\gamma n}\left(x^{\lambda n}, x^{\gamma n}\right)=1+H\left(g^{n}\right) \\
& W^{\lambda y}\left(x^{\lambda y}, x^{\gamma y}\right)=\delta+1-q+H\left(g^{y}\right) \text { if } x^{\gamma y} \geq \hat{e} \\
& W^{\gamma y}\left(x^{\lambda y}, x^{\gamma y}\right)=\delta+1+\gamma-\tau+H\left(g^{y}\right) \text { if } x^{\gamma y} \geq \hat{e} \\
& W^{\lambda y}\left(x^{\lambda y}, x^{\gamma y}\right)=W^{\gamma y}\left(x^{\lambda y}, x^{\gamma y}\right)=\delta+1 \text { if } x^{\gamma y}<\hat{e}
\end{aligned}
$$

where $g^{n}$ and $g^{y}$ are known functions of $x^{p z}$ through (1)-(2). As stated in the text, $\delta^{p}$ is obtained from (9) setting $W^{p n}=W^{p y}$. Exploiting (9), some simple algebra completes the proof.

\subsubsection{Proof of Proposition 2}

We consider each equilibrium separately

Equilibrium with Full Sorting By (9), the value of $\delta$ that leaves type $\gamma$ indifferent between the clan and the Corporation is:

$$
\begin{aligned}
\delta^{\gamma} & =\tau-\gamma+H\left(g^{n}\right)-H\left(g^{y}\right) \\
& =\tau-\gamma+H\left(\tau x^{\lambda}\right)-H\left[M \tau\left(1-x^{\lambda}\right)-e\right]
\end{aligned}
$$

for $x^{\gamma}=1-x^{\lambda} \geq \hat{e} \equiv e / M \tau$ where the second equation follows from (1), (2), (6). Clearly, equation (10) defines an implicit function $\delta^{\gamma}=D^{s}\left(x^{\lambda}\right)$, where the $s$ superscript is a reminder that this is the full sorting equilibrium. By (10):

$$
\frac{\partial \delta^{\gamma}}{\partial x^{\lambda}} \equiv D_{x}^{s}=\tau\left[H_{g}\left(g^{n}\right)+M H_{g}\left(g^{y}\right)\right]>0
$$

The equilibrium conditions discussed above require:

$$
0 \geq D^{s}\left(x^{\lambda}\right) \geq 1 / d-a
$$

which by (11) is satisfied only for some values of $x^{\lambda}$. Specifically, implicitly define $\bar{x}$ and $\underline{x}$ by:

$$
\begin{aligned}
& D^{s}(\bar{x})=0=\tau-\gamma+H(\tau \bar{x})-H[M \tau(1-\bar{x})-e] \\
& D^{s}(\underline{\mathrm{x}})=1 / d-a=\tau-\gamma+H(\tau \underline{\mathrm{x}})-H[M \tau(1-\underline{\mathrm{x}})-e]
\end{aligned}
$$

By (11), $\bar{x}>\underline{x}$. Then an equilibrium with full sorting exists if $x^{\lambda} \in[\underline{\mathrm{x}}, \bar{x}]$. Furthermore, (10) implies that:

$$
1-\hat{e}>\bar{x}>1 / 2>\underline{x}>0
$$


if the following conditions are satisfied (each condition corresponds to one of the above inequalities in the same order):

$$
\begin{aligned}
\tau-\gamma+H(\tau(1-\hat{e})) & >0 \\
\tau-\gamma+H(\tau / 2)-H(M \tau / 2-e) & <0 \\
\lambda+q-\tau+H(\tau / 2)-H(M \tau / 2-e) & >1 / d \\
\lambda+q-\tau-H(M \tau-e) & <1 / d
\end{aligned}
$$

Finally, note that in this equilibrium with full sorting, the fraction of each dynasty living in the Corporation is:

$$
x^{y}=x^{\gamma}=\left(1-x^{\lambda}\right) \equiv G^{s}\left(x^{\lambda}\right)
$$

hence it moves one for one in the opposite direction with changes in the fraction of clannish types in the population. Summarizing the above discussion:

Suppose that (A1)-(A4) hold. Then an equilibrium with full sorting exists if and only if $x^{\lambda} \in[\underline{\mathrm{x}}, \bar{x}]$, where $1-\hat{e}>\bar{x}>1 / 2>\underline{\mathrm{x}}>0$. In this equilibrium the fraction of each dynasty living in the Corporation is $x^{y}=G^{s}\left(x^{\lambda}\right)$ given by (14), and it varies inversely with $x^{\lambda}$ over the range $x^{y} \in[(1-\bar{x}),(1-\underline{\mathrm{x}})]$

Equilibrium with segregation in the clan Next, consider the equilibrium where the clannish types are segregated in the clan, while the generalists are present in both communities. Repeating the previous steps, the value of $\delta$ that leaves type $\gamma$ indifferent between the clan and the Corporation is:

$$
\begin{aligned}
\delta^{\gamma} & =\tau-\gamma+H\left(g^{n}\right)-H\left(g^{y}\right) \\
& =\tau-\gamma+H\left(\tau x^{\lambda}\right)-H\left[M \tau\left(1-d \delta^{\gamma}\right)\left(1-x^{\lambda}\right)-e\right]
\end{aligned}
$$

where the second equation follows from (1), (2), (6), having used:

$$
\left.x^{\gamma y}=x^{\gamma}-x^{\gamma n}=\left(1-d \delta^{\gamma}\right)\left(1-x^{\lambda}\right)\right)
$$

by (6). Again, equation (15) defines a known function $\delta^{\gamma}=D^{c}\left(x^{\lambda}\right)$. By the implicit function theorem applied to (15):

$$
\frac{\partial \delta^{\gamma}}{\partial x^{\lambda}} \equiv D_{x}^{c}=\frac{\tau\left[H_{g}\left(g^{n}\right)+M\left(1-d \delta^{\gamma}\right) H_{g}\left(g^{y}\right)\right]}{1-d\left(1-x^{\lambda}\right) M \tau H_{g}\left(g^{y}\right)}>0
$$

where the last inequality follows from $(\mathrm{C} 1)$ and from the fact that in this equilibrium $\delta^{\gamma} \leq$ $1 / d$. The equilibrium conditions discussed above require that the $\gamma$ types are present in both the clan and the Corporation. This requires:

$$
1 / d>D^{c}\left(x^{\lambda}\right)>0
$$

In fact, the equilibrium conditions are more stringent than that, because, Corporation size cannot be smaller than $e / M \tau \equiv \hat{e}$ in order to sustain the enforcement technology. Imposing 
this additional constraint, we have that equilibrium requires that $x^{\lambda}<1-\hat{e}$ and, by (16), that:

$$
\left(1-\frac{\hat{e}}{1-x^{\lambda}}\right) / d>D^{c}\left(x^{\lambda}\right)>0
$$

Since $a>1 / d,(18)$ then also implies that the clannish types are in all in the clan $\left(\delta^{\lambda}>1 / d\right)$.

Note that, by (15) and (13), at the point $x^{\lambda}=\bar{x}$ we have $D^{c}(\bar{x})=D^{s}(\bar{x})=0$. By (17), then, it follows that condition (18) is satisfied for at least some $x^{\lambda} \geq \bar{x}$. Since under (A1) we have that $1-\hat{e}>\bar{x}$, we know that an equilibrium with segregation in the clan exists for at least some $1-\hat{e}>x^{\lambda}>\bar{x}$. Let $x^{\max }$ be the upper bound for $x^{\lambda}$ where (18) is satisfied. By (15) and by the definition of $\hat{e}$, this upper bound is implicitly defined by the condition:

$$
\left(1-\frac{\hat{e}}{1-x^{\max }}\right) / d=\tau-\gamma+H\left(\tau x^{\max }\right)
$$

Clearly, $x^{\max }<1-\hat{e}$. Moreover, since at the point $x^{\lambda}=\bar{x}$ we have $D^{c}(\bar{x})=D^{s}(\bar{x})=0$, since $D_{x}^{c}>0$, and since by (19) $D^{c}\left(x^{\max }\right)>0$, we must also have $x^{\max }>\bar{x}$. Hence if $x^{\lambda} \in\left(\bar{x}, x^{\max }\right)$ this equilibrium with segregation in the clan exists.

Finally, note that in this equilibrium, the fraction of each dynasty living in the Corporation size is:

$$
\left.x^{\gamma y}=\left(1-d D^{c}\left(x^{\lambda}\right)\right)\left(1-x^{\lambda}\right)\right) \equiv G^{c}\left(x^{\lambda}\right)
$$

Differentiating with respect to $x^{\lambda}$ we immediately have that, by (17):

$$
G_{x}^{c}=-\left(1-d D^{c}\left(x^{\lambda}\right)-\left(1-x^{\lambda}\right) d D_{x}^{c}<0\right.
$$

Hence here too Corporation size shrinks as the proportion of clannish types in the population increases. Intuitively, as $x^{\lambda}$ rises, the clan becomes more attractive because all the clannish population is segregated in the clan and they all contribute to the public good. This draws more generalists in the clan, which makes the Corporation even less attractive compared to the clan (because public good provision in the Corporation shrinks). Equilibrium is restored when the idiosyncratic value of the preference parameter $\delta$ has risen enough for pivotal individual (i.e. when $\delta^{\gamma}$ is high enough) - by assumption (C1) and by (17) we know that this will eventually happen. Summarizing the above discussion:

Suppose that (A1)-(A4) hold. Then an equilibrium with segregation in the clan exists if and only if $x^{\lambda} \in\left(\bar{x}, x^{\max }\right)$, where $1-\hat{e}>x^{\max }>\bar{x}>1 / 2$. In this equilibrium the fraction of each dynasty living in the Corporation is $x^{y}=G^{c}\left(x^{\lambda}\right)$ given by (20), and it varies inversely with $x^{\lambda}$ over the range $x^{y} \in(\hat{e},(1-\bar{x}))$.

Equilibrium with segregation in the Corporation Finally, consider the equilibrium where the generalist types are segregated in the clan, while the clannish are present in both communities. Repeating the previous steps, the value of $\delta$ that leaves type $\lambda$ indifferent between the clan and the Corporation is:

$$
\begin{aligned}
\delta^{\lambda} & =q+\lambda-\tau+H\left(g^{n}\right)-H\left(g^{y}\right) \\
& =q+\lambda-\tau+H\left(\tau d \delta^{\lambda} x^{\lambda}\right)-H\left[M \tau\left(1-x^{\lambda}\right)-e\right]
\end{aligned}
$$


where the second equation follows from (1), (2), (6), having used:

$$
x^{\lambda n}=d \delta^{\lambda} x^{\lambda}
$$

by (6). Again, equation (22) defines a known function $\delta^{\lambda}=D^{e}\left(x^{\lambda}\right)$. By the implicit function theorem applied to (22):

$$
\frac{\partial \delta^{\lambda}}{\partial x^{\lambda}} \equiv D_{x}^{e}=\frac{\tau\left[d \delta^{\lambda} H_{g}\left(g^{n}\right)+M H_{g}\left(g^{y}\right)\right]}{1-d x^{\lambda} \tau H_{g}\left(g^{y}\right)}>0
$$

where the last inequality follows from (C1). The equilibrium conditions discussed above require that the $\lambda$ types are present in both the clan and the Corporation. This requires:

$$
1 / d>D^{e}\left(x^{\lambda}\right)>0
$$

Since $a>/ 1 / d,(25)$ then also implies that the generalist types are in all in the Corporation $\left(\delta^{\gamma}<0\right)$.

Note that, by (22) and (13), at the point $x^{\lambda}=\underline{\mathrm{x}}$ we have $D^{e}(x)=D^{s}(x)+a=1 / d$ (i.e. all clannish types are in the clan) By (24), then, it follows that condition (25) is satisfied for at least some $x^{\lambda} \leq \underline{x}$. Since under (A4) we have that $\underline{x}>0$, we know that an equilibrium with segregation in the clan exists for at least some $x^{\lambda}<\underline{x}$. Let $x^{\text {min }}$ denote the minimum value of $x^{\lambda}$ below which all clannish types are attracted to the Corporation. By $(25), x^{\min }$ is defined implicitly by:

$$
0=q+\lambda-\tau+H\left(\tau d \delta^{\lambda} x^{\min }\right)-H\left[M \tau\left(1-x^{\min }\right)-e\right]
$$

By (13) we know that $x^{\text {min }}<\underline{\mathrm{x}}$, but we cannot tell whether $x^{\text {min }}>0$ or $x^{\text {min }}=0$.

Finally, note that in this equilibrium, the fraction of each dynasty living in the Corporation is:

$$
x^{y}=\left(x^{\gamma}+x^{\lambda y}\right)=1-d D^{e}\left(x^{\lambda}\right) x^{\lambda} \equiv G^{e}\left(x^{\lambda}\right)
$$

Differentiating with respect to $x^{\lambda}$ we immediately have that, by (24):

$$
G_{x}^{e}\left(x^{\lambda}\right)=-d D^{e}\left(x^{\lambda}\right)-x^{\lambda} d D_{x}^{e}<0
$$

Hence here too Corporation size shrinks as the proportion of clannish types in the population increases. Intuitively, as $x^{\lambda}$ rises, the clan becomes more attractive because more of the clannish are present in the clan and they contribute to the public good. This draws more clannish types from the Corporation into the clan. Equilibrium is restored when the idiosyncratic value of the preference parameter $\delta$ has risen enough for pivotal individual (i.e. when $\delta^{\lambda}$ is high enough) - by assumption (C1) and by (24) we know that this will eventually happen. Summarizing the above discussion:

Suppose that (A1)-(A4) hold. Then an equilibrium with segregation in the Corporation exists if and only if $x^{\lambda} \in\left(x^{\mathrm{min}}, x\right)$, where $\underline{\mathrm{x}}>x^{\mathrm{min}} \geq 0$. In this equilibrium the fraction of each dynasty living in the Corporation is $x^{y}=G^{e}\left(x^{\lambda}\right)$ given by (26), and it varies inversely with $x^{\lambda}$ over the range $x^{y} \in((1-\underline{x}), 1)$. 


\subsubsection{Proof of Proposition 4}

Consider the equilibrium with segregation in the clan. Here equilibrium clan size is $x_{t}^{n}=$ $1-x_{t}^{\gamma y}=1-G^{c}\left(x_{t}^{\lambda}\right)$. Hence (8) can be re-written as:

$$
\begin{aligned}
x_{t+1}^{\lambda} & =(1-\bar{p})+(\bar{p}+\underline{p}-1) x_{t}^{\lambda}+(\bar{p}-\underline{p})\left(1-G^{c}\left(x_{t}^{\lambda}\right)\right) \\
& =(1-\bar{p})+\left[2 \bar{p}-1-(\bar{p}-\underline{p}) D^{c}\left(x_{t}^{\lambda}\right)\right] x_{t}^{\lambda}+(\bar{p}-\underline{p}) D^{c}\left(x_{t}^{\lambda}\right)
\end{aligned}
$$

where the last equality follows from (20). Denoting by $\delta_{s}^{c} \equiv D^{c}\left(x_{s}^{\lambda}\right)$ the steady state value of $\delta^{\gamma}$ in this equilibrium, we can express the steady state fraction of the clannish types by:

$$
x_{s}^{\lambda}=\frac{1-\bar{p}+(\bar{p}-\underline{p}) \delta_{s}^{c}}{2(1-\bar{p})+(\bar{p}-\underline{p}) \delta_{s}^{c}} \equiv x^{\lambda c}>1 / 2
$$

where the last inequality follows by noting that in this equilibrium $\delta_{s}^{c}>0$. Thus, in this steady state more than half the population ends up being clannish. The reason is that even some generalists are attracted to the clan, which in turn influences the preferences of their offspring towards the clannish type. Since the steady state is jointly determined by (29) and (15), that implicitly defines $\delta_{s}^{c}=D^{c}\left(x^{\lambda}\right)$, in this equilibrium the steady state is affected by changes in parameters of the static model, since the distribution of types across communities is endogenous, and in turn it influences the evolution of preferences.

Is this steady state stable? Differentiating (28) with respect to $x_{t}^{\lambda}$, we obtain:

$$
\begin{aligned}
\frac{\partial x_{t+1}^{\lambda}}{\partial x_{t}^{\lambda}} & =(\bar{p}+\underline{p}-1)-(\bar{p}-\underline{p}) G_{x}^{c}= \\
& =(\bar{p}+\underline{p}-1)+(\bar{p}-\underline{p})\left[\left(1-d D^{c}\left(x_{t}^{\lambda}\right)\right)+\left(1-x_{t}^{\lambda}\right) d D_{x}^{c}\right]
\end{aligned}
$$

where the second equality follows from (21). Since both terms on the right hand side of (30) are positive, the dynamics is monotonic. If the right-most term is not too large in the neighborhood of the steady state (or if $\bar{p}-\underline{p}$ is sufficiently small), then the right hand side of (30) is also smaller than unity, so that the steady state is locally stable. Thus, if $x^{\lambda c} \in\left(\bar{x}, x^{\max }\right)$ defined in the previous subsection, then for any initial condition in this same interval $\left(\bar{x}, x^{\max }\right)$, the economy remains in the equilibrium with segregation in the clan and eventually reaches the steady state. Recalling that $\left(1-\frac{\hat{e}}{1-x^{\max }}\right) / d>D^{c}\left(x^{\lambda}\right)>0$, and using (29), a sufficient condition for $x^{\lambda c}<x^{\max }$ is:

$$
x^{\max }>\frac{1-\underline{p}-(\bar{p}-\underline{p}) \hat{e}}{2-\bar{p}-\underline{p}}
$$

QED. 


\subsubsection{Proof of Proposition 5}

Finally, consider the equilibrium with segregation in the Corporation. Here equilibrium clan size is $x_{t}^{n}=1-x_{t}^{y}=1-G^{e}\left(x_{t}^{\lambda}\right)$. Hence (8) can be rewritten as:

$$
\begin{aligned}
x_{t+1}^{\lambda} & =(1-\bar{p})+(\bar{p}+\underline{p}-1) x_{t}^{\lambda}+(\bar{p}-\underline{p})\left(1-G^{e}\left(x_{t}^{\lambda}\right)\right) \\
& =(1-\bar{p})+\left(\bar{p}+\underline{p}-1+(\bar{p}-\underline{p}) d D^{e}\left(x_{t}^{\lambda}\right)\right) x_{t}^{\lambda}
\end{aligned}
$$

where the last equality follows from (26). We can thus express the steady state fraction of clannish types in this equilibrium as:

$$
x_{s}^{\lambda}=\frac{1-\bar{p}}{2-\bar{p}-\underline{p}-(\bar{p}-\underline{p}) d \delta_{s}^{e}} \equiv x^{\lambda e}<1 / 2
$$

where $\delta_{s}^{e} \equiv D^{e}\left(x_{s}^{\lambda}\right)$ and where the last inequality follows by noting that in this equilibrium $\delta_{s}^{e}<1 / d$. Thus, in this steady state less than half the population ends up being clannish. The reason is that some clannish types are attracted to the Corporation, which in turn influences the preferences of their offspring towards the generalist type. Since the steady state is jointly determined by (32) and (22), that implicitly defines $\delta_{s}^{e}=D^{e}\left(x_{s}^{\lambda}\right)$, in this equilibrium too the steady state is affected by changes in parameters of the static model, since the distribution of types across communities is endogenous, and in turn it influences the evolution of preferences.

To assess stability, again differentiate (31) with respect to $x_{t}^{\lambda}$, to obtain:

$$
\begin{aligned}
\frac{\partial x_{t+1}^{\lambda}}{\partial x_{t}^{\lambda}} & =(\bar{p}+\underline{p}-1)-(\bar{p}-\underline{p}) G_{x}^{e}= \\
& \left.=(\bar{p}+\underline{p}-1)-(\bar{p}-\underline{p}) d\left[D^{e}\left(x_{t}^{\lambda}\right)\right)+x_{t}^{\lambda} D_{x}^{e}\right]
\end{aligned}
$$

where the second equality follows from (27). If the right-most term is not too large in absolute value in the neighborhood of the steady state (or if $\bar{p}-\underline{p}$ is sufficiently small), then the right hand side of (33) is also smaller than unity, so that the steady state is locally stable. Moreover, if $\bar{p}-\underline{p}$ is sufficiently small, then the right hand side of (33) is also positive, so that the dynamics is also monotonic. Thus, if $x^{\lambda e} \in\left(x^{\min }, \underline{\mathrm{x}}\right)$ defined in the previous subsection, then for any initial condition in this same interval $\left(x^{\min }, \underline{\mathrm{x}}\right)$, the economy remains in the equilibrium with segregation in the Corporation and eventually reaches the steady state. QED. 